\title{
Start-Up Subsidies for the Unemployed: Long-Term Evidence and Effect Heterogeneity
}

\author{
Marco Caliendo* \\ Steffen Künn ${ }^{\dagger}$
}

March 23, 2010

\begin{abstract}
Turning unemployment into self-employment has become an increasingly important part of active labor market policies (ALMP) in many OECD countries. Germany is a good example where the spending on start-up subsidies for the unemployed accounted for nearly $17 \%$ of the total spending on ALMP in 2004. In contrast to other programs - like vocational training, job creation schemes, or wage subsidies - the empirical evidence on the effectiveness of such schemes is still scarce; especially regarding long-term effects and effect heterogeneity. This paper aims to close this gap. We use administrative and survey data from a large sample of participants in two distinct start-up programs and a control group of unemployed individuals. We find that over $80 \%$ of participants are integrated in the labor market and have relatively high labor income five years after start-up. Additionally, participants are much more satisfied with their current occupational situation compared to previous jobs. Based on conditional propensity score matching methods we estimate the long-term effects of the programs against non-participation. Our results show that both programs are effective with respect to income and employment outcomes in the long-run. Moreover, we consider effect heterogeneity with respect to several dimensions and show that start-up subsidies for the unemployed tend to be most effective for disadvantaged groups in the labor market.
\end{abstract}

Keywords: Start-Up Subsidies, Self-Employment, Evaluation, Long-Term Effects, Effect Heterogeneity.

JEL codes: J68, C14, H43.

\footnotetext{
*IZA, DIW Berlin, IAB, e-mail: caliendo@iza.org. Corresponding address: Institute for the Study of Labor (IZA), P.O. Box 7240, 53072 Bonn, Germany.

${ }^{\dagger}$ IZA, FU Berlin, e-mail: kuenn@iza.org
}

The authors thank Ricarda Schmidl for helpful comments and suggestions. We also thank the participants in seminars and conferences at IZA, University of Kiel, University of Cracow, the 2009 IZA/Worldbank conference (Bonn), the 2009 SOLE conference (Boston), the 2009 ESPE conference (Sevilla) and the 2009 AIEL conference (Sassari) for valuable comments. Financial support of the IAB (Nuremberg) under the research grant No. 1007 is gratefully acknowledged. 


\section{Introduction}

The recent OECD report on income and poverty (OECD, 2008) illustrates an increase in poverty rates over the past decade, where the risk of becoming poor shifted from the elderly in particular towards children and people of working age. The importance of employment in this context is straightforward as poverty among non-working households increased sharply during the last decade. The poverty rate $^{1}$ for households where the head is of working age but no household member actually works amounted to $36 \%$ and was three (twelve) times higher than for households with one (two or more) worker in the mid-2000s. Despite cross-country variation in terms of the scope of poverty, the negative correlation between employment rates and poverty is throughout valid. In an earlier study, Sen (1997) presents different concepts on how unemployment may cause poverty and inequality due to social exclusion. The main idea is that specific groups of individuals are generally excluded from the labor market, for example low skilled or youth. In addition, economic conditions may also foster social exclusion. He argues that along with the abolishment of social exclusion, unemployment and therefore poverty will be reduced. Governments are fully aware of this concept and therefore spend significant amounts of their budget on active labor market policies (ALMP) to equalize labor market conditions of unemployed individuals, in which a special focus is usually put on disadvantaged groups. By removing severe differences in terms of education, work experience or productivity, existing labor market barriers are to be overcome, consequently reducing unemployment. Several labor market programs have been introduced in which the most popular programs are traditionally training measures such as retraining, classroom training or on-the-job training. Furthermore, employment subsidies, job creation schemes and job-search assistance have also been adapted by almost all OECD countries. These programs are supposed to integrate unemployed individuals in the labor market and are associated with an upward shift in income level to secure one's livelihood and an increase in life and job satisfaction. Much research has been dedicated to investigating the effectiveness of ALMP programs. Although positive results with respect to income and employment prospects were found occasionally, the overall evidence indicates that the effects of those traditional measures are rather disappointing (see Martin and Grubb, 2001; Dar and Gill, 1998; Dar and Tzannatos, 1999; or Fay, 1996 for evidence on OECD countries and Kluve and Schmidt, 2002 for the European experience). In particular, job creation schemes turn out to be not appropriate for improving participants' employment perspectives.

On the other hand, it is found that the promotion of self-employment among unemployed individuals is a promising tool. Public authorities usually tie start-up subsidies with the hope for a "double dividend". Besides creating a job for the self-employed themselves, the newly founded businesses may potentially create further jobs and thus reduce unemployment rates even further. Moreover, individuals who receive support also increase their employability, human capital and labor market networks during the period of selfemployment, which, in the case of failure, makes them more able to find regular employ-

\footnotetext{
${ }^{1}$ The poverty rate is defined as the share of people with an equivalised disposable income below $50 \%$ of the median of the entire population.
} 
ment. Start-up subsidies may also be promising from a macroeconomic perspective, since the entry of new firms generally increases competition and consequently productivity of firms. This potentially can promote efficient markets and technology diffusion and might finally lead to economic stability and economic growth, i.e., an increase in wealth (see Storey, 1994; Fritsch, 2008). However, there are also some concerns related to financial promotion of start-ups by the unemployed. First of all, supported individuals may have become self-employed even without financial support. This is referred to as deadweight loss and is usually hard to determine. ${ }^{2}$ Another concern addresses crowding out effects, whereby incumbent or non-subsidized firms may be displaced by supported start-ups. Finally, firms may also substitute employees with subsidized self-employed workers. Due to a highly regulated labor market in Germany, however, such substitution effects are likely to play only a minor role in practice.

We focus in our analysis on the effects of start-up subsidies on the participating individuals only, that is we do not address any macroeconomic or general-equilibrium effects. Most of the existing evaluation studies on start-up schemes report positive effects with respect to different labor market outcomes. The evidence varies with respect to countries and institutional design of support. A main shortcoming of previous studies is that they provide short to medium-run evidence only and - especially in the case of industrialized countries - do not consider effect heterogeneity. If the analysis is conducted at a point at which individuals still receive the support, the results are likely to be upward biased due to locking-in effects. To properly judge the effects of the programs, the observation window needs to be (substantially) longer than the period of support. Furthermore, it can be assumed that there will be heterogeneity in the effects of these programs, which implies that some groups might benefit more and others less from participation. This is of special interest for particular disadvantaged groups, for example low educated or young individuals who are over-represented among the long-term unemployed and socially excluded. Knowing how start-up schemes work for these groups will help to design programs more appropriate and thereby tackle long-term unemployment, social exclusion, and the associated risk of poverty.

The aim of this paper is to close the existing research gap by providing long-term evidence and an extensive analysis with respect to effect heterogeneity for two distinct start-up subsidies for unemployed individuals in Germany. The first program-bridging allowance (BA, "Überbrückungsgeld") — provided relatively high financial support (depending on individuals' previous earnings) to unemployed workers for six months; whereas the second program - start-up subsidy (SUS, "Existenzgründungszuschuss") — consisted of (lower) monthly lump-sum payments for up to three years. ${ }^{3}$ Since both schemes differ sharply in terms of financial support and duration, they also attracted different types of individuals. Using a combination of administrative and survey data, we are able to follow individuals for nearly five years after entering the programs. In addition, we also have access to a suitable control group of other unemployed individuals allowing us to use

\footnotetext{
${ }^{2}$ Meager (1993) provides an estimate of the deadweight effect related to the bridging allowance in Germany and concludes that the effect is rather small (about 10\%).

${ }^{3}$ Both programs were replaced in August 2006 by a single new program - the new start-up subsidy program (Gründungszuschuss)—which will not be analyzed here.
} 
conditional propensity score matching methods for the impact analysis. We find strong positive long-run effects for both programs with respect to several labor market outcomes. In addition, we show that they are most effective for individuals at high risk of being excluded from the labor market, i.e., low educated and low qualified individuals.

The paper is organized as follows: Section 2 provides a brief literature review on ALMP in OECD countries, institutional details on start-up programs for the unemployed in Germany and a discussion of previous results on such measures. Afterwards we describe the data, discuss descriptive results and illustrate the identification and estimation strategy in Section 3. The main results are discussed in Section 4, which also contains an extensive analysis of effect heterogeneity. Finally, we test our results with respect to unobserved heterogeneity before we conclude in Section 5 .

\section{ALMP to Reintegrate Unemployed Individuals}

\subsection{Previous Literature}

The OECD reports an average spending of $0.6 \%$ of a country's GDP on ALMP among all OECD member states in 2007, and therefore, much research has been conducted investigating the effectiveness of such measures (see OECD, 2009). The main question is whether ALMP programs are appropriate for improving participants' labor market perspectives and in addition whether they also generate income gains for participants. For instance, Martin and Grubb (2001), Dar and Tzannatos (1999) and Fay (1996) review evaluation studies on ALMP across OECD countries and present mixed results for several programs. In fact, they do find some positive results for certain subgroups, for example training for the long-term unemployed, or women. Dar and Gill (1998) consider retraining programs in OECD countries and are not able to identify significant effects. Focusing on Europe, Kluve and Schmidt (2002) find strong heterogenous effects for different programs and subgroups and argue that job search assistance and training might be effective. Card, Kluve, and Weber (2009) provide an international meta-analysis of recent evaluation studies on the effectiveness of ALMP programs and confirm the overall ineffectiveness of job creation schemes. Moreover, they find promising effects for classroom or on-the-job training in the medium-run. In an earlier review on the US and European experience, Heckman, LaLonde, and Smith (1999) point out that benefits from ALMP programs do not significantly reduce poverty or unemployment, however, employment gains are more likely to occur as an increase in income levels. Betcherman, Olivas, and Dar (2004) provide an overview on the effectiveness of ALMP in developing and transition countries and find some positive results for employment services while training measures, public works and wage subsidies are rather unsuccessful. For Germany, Fitzenberger, Osikominu, and Völter (2008) and Lechner, Miquel, and Wunsch (2004) find positive effects for training measures in the long-run. Moreover, Stephan (2008) and Stephan and Pahnke (2008) provide evidence for vocational training, short-term training, wage subsidies and job creation schemes and show consistently negative effects for job creation schemes (in line with Caliendo, Hujer, and Thomsen, 2008) and mostly positive but not always significant effects for the other 
programs under consideration. Lechner and Wunsch (2008) conclude that programs such as vocational training, wage subsidies, short-term training and assessment schemes are overall ineffective for the West German labor market. To sum up, despite occasionally positive results, the overall evidence indicates that traditional measures are rather disappointing. In particular job creation schemes turned out to be not appropriate for improving participants' employment prospects, and training programs bring modest effects only in the (very) long-run.

In light of these findings, supporting unemployed individuals in becoming self-employed might be promising tool among active labor market policies. The international evidence is still relatively scarce on such measures but predominantly indicates positive results. For developing countries, for instance, Almeida and Galasso (2007) investigate the impact of financial and technical assistance for welfare beneficiaries on their way to self-employment in Argentina. They observe a period of 12 months in 2004/2005 and find an increase in total working hours but no significant income effects due to the program. However, for young and highly educated individuals they are able to identify positive income effects. Rodriguez-Planas (2008) investigates a start-up program for Romania in which the participants obtained professional assistance through counseling or short-term entrepreneurial training. In addition, working capital loans were offered. She identifies positive employment effects but no income gains for participants compared to non-participants and reveals strong positive employment effects for a subgroup of low educated individuals. O'Leary (1999) considers self-employment schemes for Poland and Hungary. The scheme in Poland provides loans at market interest rates to the unemployed combined with the attractive option that $50 \%$ of repayments will be waived if firms survive at least two years. In contrast, the Hungarian program consists of unemployment benefits paid up to 18 months. In addition, it also incurs half of the costs for training and counseling. O'Leary (1999) finds large and positive employment effects for both countries. Whilst he is also able to identify strong positive earning effects for Hungary, the income effect in Poland is negative. ${ }^{4}$ Among participants, O'Leary (1999) finds high survival rates in self-employment and additional employment effects in both countries. The findings are similarly positive for developed countries. Carling and Gustafson (1999) provide a comparative study between employment subsidies and self-employment grants for the unemployed in Sweden. They find that individuals in subsidized employment have a higher probability of re-entering unemployment than recipients of self-employment grants. Therefore, they conclude that self-employment grants are more effective in avoiding unemployment. Cueto and Mato (2006) analyze the success of self-employment subsidies for particular districts in Spain. They find survival rates of approximately $93 \%$ after two years and $76 \%$ after five. For New Zealand, Perry (2006) evaluates enterprise allowance grants, an integrated program that provides business skills training as well as financial aid. The author's results indicate a decrease in time registered as unemployed for participants. Meager, Bates, and Cowling (2003) evaluate business start-up subsidies by the Prince Trust to young people in the UK. The authors conclude that participating in the programme does not have any significant

\footnotetext{
${ }^{4}$ O'Leary (1999) primarily attributes the negative earning effect in the case of Poland to firms' reluctance in full disclosure to the tax authorities.
} 
impact on subsequent employment or earning chances. Nonetheless, descriptively they find a fraction of $69.1 \%$ in self-employment among participants after 18 months. Kelly, Lewis, Mulvey, and Dalzell (2002) consider an allowance paid up to 52 weeks as well as training and counseling in Australia. The authors find a survival rate of $56.2 \%$ in self-employment after three years following start-up.

In a study for Germany which is very closely related to ours, Baumgartner and Caliendo (2008) provide an evaluation of BA and SUS programs for the short and medium-run. They find strong positive employment and income effects for participants compared to a group of non-participants. However, the authors underscore the preliminary character of their results, as the majority of start-up subsidy participants still received financial support during the observation period. Therefore, the survival rate is likely to further decrease after financial support completely expires. In an earlier study, Pfeiffer and Reize (2000) analyze the effect of BA on survival rates in self-employment during the first year after entry. They find neither differences in survival probability nor in employment growth between supported and non-subsidized firms in West Germany.

To summarize, the existing literature on start-up schemes for the unemployed mainly reports either positive or insignificant effects with respect to different labor market outcomes; whilst negative impacts are scarce. Effect heterogeneity is considered only by studies on developing countries. The evidence varies with respect to countries, institutional design of the support and entrance conditions. However, the main shortcoming is that existing studies provide evidence for the short to medium-run only. Long-term evidence is indeed highly demanded by the literature but - due to data limitations - still missing. We are now able to observe supported firms up to five years since start-up and hence contribute long-term evidence to the literature. Moreover, we show in an extensive analysis with respect to effect heterogeneity for which subgroups of individuals such programs are most effective.

\subsection{Institutional Settings in Germany}

Before heading to the empirical section, we discuss the institutional settings of start-up programs for the unemployed in Germany. The bridging allowance, introduced in 1986, remained the only program providing support to unemployed individuals who wanted to start their own business until 2003. Its main goal was to cover basic costs of living and social security contributions during the initial stages of self-employment. The recipient of BA received the same amount during the first six months he or she would have received if unemployed. Since the unemployment scheme also covers social security contributions (including health insurance, retirement insurance, etc.) a lump sum for social security is granted equal to $68.5 \%$ of the unemployment support that would have been received. Unemployed individuals were entitled to BA on condition of their business plan being externally approved, usually by the regional chamber of commerce. Thus, approval of an individual's application did not depend on the case manager at the local labor office. In January 2003, an additional program was initiated to support unemployed people in starting a new business. This start-up subsidy was introduced as part of a large package 


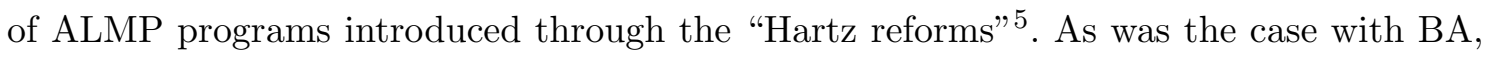
the main goal of SUS is to secure the initial phase of self-employment. It focuses on the provision of social security to the newly self-employed person. The support comprises of a lump sum payment of $€ 600$ per month in the first year. A growth barrier is implemented in SUS such that the support is only granted if income does not exceed $€ 25,000$ per year. The support shrinks to $€ 360$ per month in the second year and to $€ 240$ per month in the third. In contrast to the BA, SUS recipients have to pay into the statutory pension fund and may claim a reduced rate for statutory health insurance. When the SUS was introduced in 2003, applicants did not have to submit business plans for prior approval, but they have been required to do so since November 2004. Moreover, parallel receipt of BA and SUS is excluded. The important features of both programs are summarized in Table 1. Moreover, it should be mentioned that other institutions such as federal state governments or the chamber of commerce offer general programs to encourage self-employment, for example, counseling, preparatory courses or even capital loans. Additionally, in some professions self-employment is highly restrictive in Germany when compared to other countries. For some "typical" self-employed occupations (physicians, lawyers, etc.) and several handcraft occupations it is required to occupy an advanced certificate in order to be allowed to become self-employed. However, Cressy (1996) argues that such preconditions for entry into self-employment tend to significantly enhance survival of businesses. In addition to entry restrictions, the German system prevents entrepreneurs from founding a company again if their business went bankrupt once.

\section{INSERT TABLES 1 AND 2 ABOUt HERE}

Due to the institutional framework, it was rather rational to choose BA if unemployment benefits were fairly high or if the income generated through the start-up firm was expected to exceed $€ 25,000$ per year. Both programs were replaced in August 2006 by a single new program - the new start-up subsidy program (Gründungszuschuss) - which will not be analyzed here. ${ }^{6}$ Table 2 contains number of entries into start-up programs as well as other programs of ALMP in West Germany. It is noticeable that start-up programs are comparable in terms of number of entries to other programs of ALMP, such as wage subsidies (WS) or vocational training (VT). On the other hand, entries into training measures (TM) are more than three times as much; but, of course, one has to keep in mind that TM are rather short-term, i.e., with a maximum duration of three months and an average duration of two weeks. Accordingly, entrance requirements are much lower. As we can see, the scope of the new start-up subsidy (New SUS) is below the cumulated number of entries in BA and SUS.

\footnotetext{
${ }^{5}$ See Caliendo (2009) for an overview of the most relevant elements of the "Hartz reforms".

${ }^{6}$ The new start-up subsidy consists of unemployment benefits and a lump-sum payment of $€ 300$ per month for social coverage paid for nine months. Afterwards the lump-sum payment of $€ 300$ might be extended for further six months if the business is the full-time activity of the applicant. See Caliendo and Kritikos (2009) for information and a critical discussion of the features of the new program.
} 


\section{Data and Empirical Strategy}

\subsection{Data}

In our analysis we focus on entries into SUS and BA in the third quarter of 2003 and combine administrative data from the "Federal Employment Agency" (FEA) with a survey such that longitudinal as well as cross-section data are available. We draw on data used by Baumgartner and Caliendo (2008) and extend it with an additional interview wave. ${ }^{7}$ The administrative part consists of data based on the "Integrated Labour Market Biographies" (ILMB) of the FEA, containing relevant register data from four sources: employment history, unemployment support recipience, participation in active labor market measures, and job seeker history. Since the administrative data do not provide any information on self-employed individuals, the ILMB data are complemented by information from a computer-assisted telephone interview. For this, participants for each program who became self-employed in the third quarter of 2003 are randomly drawn. The comparison group is restricted to those who were unemployed in the third quarter of 2003, eligible to participate in either of the two programs, but did not join a program in this quarter. However, controls are allowed to participate in ALMP programs afterwards. ${ }^{8}$ The first two interviews took place in January/February of 2005 and 2006; the final one was conducted in May/June of 2008. This enables us to follow individuals up to five years after start-up.

\section{INSERT TABLE 3 ABOUT HERE}

We restrict our sample to men in West Germany for two reasons. Men are more likely to become full-time self-employed than women; and West Germany is characterized by better labor market conditions compared to East Germany. We are interested in the effectiveness of start-up schemes to integrate former unemployed individuals in the labor market and we avoid several side-effects, such as labor supply decisions, macroeconomic constraints and so on, by excluding women and the East German labor market. Table 3 provides the number of realized interviews in the respective waves. In the case of SUS, for instance, we initially started with 1,116 individuals who became self-employed in the third quarter of $2003 ; 811$ responded to the second interview and finally we end up with 486 after the last interview in 2008. Hence, our final sample consists of 486 participants in SUS, 780 recipients of BA and 929 non-participants.

\subsection{Descriptive Evidence}

Table A.1 in the Appendix provides descriptive statistics measured at entry into program in the third quarter of 2003 separately for participants (SUS and BA) and non-participants. Participants in SUS are on average younger and lower educated individuals with less

\footnotetext{
${ }^{7}$ Therefore, we only briefly discuss the basic data construction and refer to Baumgartner and Caliendo (2008) for a more extensive discussion of the data issues.

${ }^{8}$ The actual number of non-participants who participated in ALMP programs after the third quarter 2003 is rather low. Approximately $15 \%$ of all non-participants were assigned to programs of ALMP and only $2 \%$ participated in SUS or BA within our observation period.
} 
employment duration and lower earnings in the past. This is in line with our expectations, as the financial support in case of BA depends on previous earnings and is only paid for a short period of six months. Hence, individuals with low earnings in the past are only eligible to minor support if they choose BA. It is therefore rational for those individuals to choose SUS because the subsidy is small but it might be extended up to three years. On the other hand, individuals with higher earnings want to secure their high entitlement and, consequently, choose BA. Moreover, in terms of location participants seem to be equally distributed throughout West Germany. As pointed out in previous research (e.g. Dunn and Holtz-Eakin, 2000), we find that self-employment is influenced by intergenerational transmission, i.e., the fraction with parental self-employment among participants is higher than among non-participants.

\section{INSERT TABLE 4 ABOUT HERE}

In Table 4 we provide the labor market status of participants and non-participants after 28 and 56 months following start-up and the monthly income after 56 months. All descriptive results are weighted using sequential inverse probability weighting to adjust for the selection process due to panel attrition (see Wooldridge, 2002). ${ }^{9}$ First of all, a closer look at the labor market developments of participants reveals that the fraction of selfemployed individuals decreases from $71.5 \%$ to $67.9 \%$ for former BA recipients and from $67.6 \%$ to $59.7 \%$ for firms initially supported by SUS. Hence, the decline in self-employment is more than twice as high for SUS (-7.9 percentage points) than for BA (-3.6 percentage points) in the given period. This is mainly due to the fact that SUS expired between the second and third interview; whereas BA support had already stopped after six months, that was before the first interview took place. The sharp drop in self-employment rates after the end of the subsidy period may be seen as indication that some businesses were only able to survive with the help of the subsidy.

However, the main objective of ALMP is not primarily to create self-employment but to integrate unemployed individuals into the labor market. Hence, we now consider the share of individuals either in self-employment or regular employment. After 56 months since start-up, we find about $81 \%$ of SUS and $89 \%$ of former BA participants well integrated in the labor market. For non-participants, only $63 \%$ are either self-employed or regularly employed. Hence, we observe a raw difference of employment rates of about $20 \%$ between participants and non-participants. These are descriptives only and the gap is potentially caused by differences in key variables. We return to this point in Section 3.3 when discussing the identification strategy and finally present causal effects of the programs in Section 4.1.

\footnotetext{
${ }^{9}$ As we can see in Table 3 the number of realized interviews decreased partly dramatically. On average, we are only able to observe $45 \%$ of all participants and $37 \%$ of non-participants for the entire period of 56 months. We checked our results with respect to potential selection process due to panel attrition and find positive selection, i.e., individuals who perform relatively well in terms of labor market outcomes are more likely to respond. Therefore, we use sequential inverse probability weighting to adjust for this selective attrition. Our matching results later on rely on unweighted outcome variables because participants and non-participants are similarly affected by selection due to panel attrition.
} 
With respect to another objective of ALMP, the achievement of certain income levels for participants, we also provide in Table 4 net income measures. Here, the income is measured 56 months after start-up. Next to working income, the total income captures transfer payments such as unemployment benefit, pension, or child benefit. We can see that former BA recipients have higher income in terms of both working and total income compared to SUS participants. This is not surprising because of the aforementioned selection into BA of highly educated individuals with high earnings in the past. It is also noticeable that non-participants earn on average less than participants; however considering the median of the income distribution, the difference to SUS participants almost vanishes.

\section{INSERT TABLE 5 ABOUT HERE}

Finally, to answer the question whether participants are more satisfied with their employment status compared to previous dependent employment, Table 5 provides some evidence on job satisfaction among participants who are self-employed at the third interview. The respondents were asked to compare their self-employment with the previous employment spell with respect to different aspects. Thereby, positive values indicate an overall improvement while negative values depict a decline. For participants in both programs, the situation improved in terms of type of activity, income and promotion prospects but declined for measures such as workload, working time and social security. However, the improvement among the first three measures is obviously more valued by individuals than the decrease in the latter because of higher absolute values.

\subsection{Identification of Causal Effects}

In order to estimate causal effects, we base our analysis on the potential outcome framework, also known as the Roy (1951) - Rubin (1974) model. The two potential outcomes are $Y^{1}$ (individual receives treatment, $D=1$ ) and $Y^{0}$ (individual does not receive treatment, $D=0$ ). The observed outcome for any individual $i$ can be written as: $Y_{i}=$ $Y_{i}^{1} \cdot D_{i}+\left(1-D_{i}\right) \cdot Y_{i}^{0}$. The treatment effect for each individual $i$ is then defined as the difference between her potential outcomes: $\tau_{i}=Y_{i}^{1}-Y_{i}^{0}$. Since we can never observe both potential outcomes for the same individual at the same time, the fundamental evaluation problem arises. We will focus on the most prominent evaluation parameter, which is the average treatment effect on the treated (ATT), and is given by:

$$
\tau_{A T T}=E\left(Y^{1} \mid D=1\right)-E\left(Y^{0} \mid D=1\right) .
$$

The last term on the right hand side of equation (1) describes the hypothetical outcome without treatment for those individuals who received treatment. Since the condition $E\left(Y^{0} \mid D=1\right)=E\left(Y^{0} \mid D=0\right)$ is usually not satisfied with non-experimental data, estimating ATT by the difference in sub-population means of participants $E\left(Y^{1} \mid D=1\right)$ and non-participants $E\left(Y^{0} \mid D=0\right)$ will lead to a selection bias. This bias arises because participants and non-participants are selected groups that would have different outcomes, 
even in the absence of the program due to observable or unobservable factors. ${ }^{10}$ We apply propensity score matching and thus rely on the conditional independence assumption (CIA), which states that conditional on observable characteristics $(W)$ the counterfactual outcome is independent of treatment: $Y^{0} \amalg D \mid W$, where $\amalg$ denotes independence. In addition to the CIA, we also assume overlap: $\operatorname{Pr}(D=1 \mid W)<1$, for all $W$. This implies that there is a positive probability for all $W$ of not participating, i.e., that there are no perfect predictors which determine participation. These assumptions are sufficient for identification of the ATT, which can then be written as:

$$
\tau_{A T T}^{M A T}=E\left(Y^{1} \mid W, D=1\right)-E_{W}\left[E\left(Y^{0} \mid W, D=0\right) \mid D=1\right]
$$

where the first term can be estimated from the treatment group and the second term from the mean outcomes of the matched comparison group. The outer expectation is taken over the distribution of $W$ in the treatment group.

As direct matching on $W$ can become hazardous when $W$ is of high dimension ("curse of dimensionality"), Rosenbaum and Rubin (1983) suggest using balancing scores $b(W)$. These are functions of the relevant observed covariates $W$ such that the conditional distribution of $W$ given $b(W)$ is independent of the assignment to treatment, that is, $W \amalg D \mid b(W)$. The propensity score $P(W)$, i.e., the probability of participating in a program, is one possible balancing score. For participants and non-participants with the same balancing score, the distributions of the covariates $W$ are the same, i.e., they are balanced across the groups. Hence, the identifying assumption can be re-written as $Y^{0} \amalg D \mid P(W)$ and the new overlap condition is given by $\operatorname{Pr}(D=1 \mid P(W))<1$.

The CIA is clearly a very strong assumption and the applicability of the matching estimator depends crucially on its plausibility. Blundell, Dearden, and Sianesi (2005) argue that the plausibility of such an assumption should always be discussed on a case-by-case basis. Only variables which simultaneously influence the participation decision and the outcome variable should be included in the matching procedure. Hence, economic theory, a sound knowledge of previous research, and information about the institutional setting should guide the researcher in specifying the model (see, e.g., Smith and Todd, 2005 or Sianesi, 2004). We use both administrative and survey data, which enables us to control for numerous individual information and labor market conditions. Based on this exhaustive data, we argue that the CIA holds in our application. However, we test the sensitivity of the results with respect to time-invariant unobserved differences between participants and non-participants by implementing conditional difference-in-differences (DID). This allows for unobservable but temporally invariant differences in outcomes between participants and non-participants, which obviously relaxes the CIA. Conditional DID was initially suggested by Heckman, Ichimura, Smith, and Todd (1998). It extends the conventional DID estimator by defining outcomes conditional on the propensity score and using semiparametric methods to construct the differences. If the parameter of interest is ATT, the

\footnotetext{
${ }^{10}$ See, for example Caliendo and Hujer (2006) for further discussion.
} 
conditional DID estimator is based on the following identifying assumption:

$$
E\left[Y_{t}^{0}-Y_{t^{\prime}}^{0} \mid P(W), D=1\right]=E\left[Y_{t}^{0}-Y_{t^{\prime}}^{0} \mid P(W), D=0\right]
$$

where $(t)$ is the post-treatment and $\left(t^{\prime}\right)$ the pre-treatment period. It also requires the common support condition to hold and can be written as:

$$
\tau_{A T T}^{C D I D}=E\left(Y_{t}^{1}-Y_{t^{\prime}}^{0} \mid P(W), D=1\right)-E\left(Y_{t}^{0}-Y_{t^{\prime}}^{0} \mid P(W), D=0\right) .
$$

For identification of causal effects, any general equilibrium effects need to be excluded, that is treatment participation of one individual can not have an impact on outcomes of other individuals. This assumption is referred to as stable-unit-treatment-value-assumption (SUTVA). Imbens and Wooldridge (2008) argue that the validity of such an assumption depends on the scope of the program as well as on resulting effects. They infer that for the majority of labor market programs, the SUTVA is potentially fulfilled because such programs are usually of small scope with rather limited effects on the individual level. We follow their argumentation and refer to Table 2, where we see that entries into SUS and BA are approximately of the same scope as other ALMP programs and in relation to the total number of entries into unemployment of 5.5 million in 2004 quite small.

\subsection{Estimation Procedure}

After having discussed identification issues, we proceed with the estimation of causal effects. We apply propensity score matching and estimate the propensity scores for participation in the respective program versus non-participation using probit-estimation. We test different specifications following economic theory and previous empirical findings as discussed above. But we also check econometric indicators such as significance of parameters or pseudo- $R^{2}$ to find the final specification. ${ }^{11}$ The results of the probit-estimation can be found in Table A.2 in the Appendix. Let us briefly discuss the main components that influence the selection into treatment. In particular, variables such as age, duration of previous unemployment, regional cluster, information with respect to previous earnings and the intergenerational transmission turn out to be most important for the selection into SUS. In the case of "BA vs. NP", the duration of previous unemployment, indicators for the labor market history and also parental self-employment have a significant impact. This actually confirms our expectation that individuals with higher previous earnings are more likely to choose BA. In addition, we also provide the distribution of the estimated propensity scores in Figure A.1 in the Appendix. As we can see, the distribution of the propensity scores are biased towards the tails, that is participants have a higher probability on overage of becoming self-employed than non-participants. Nevertheless, participant's propensity score distribution overlaps the region of the propensity scores of non-participants completely; therefore, the overlap assumption is fulfilled.

\footnotetext{
${ }^{11}$ For a more extensive discussion on the estimation of propensity scores, we refer to Heckman, Ichimura, Smith, and Todd (1998) and Caliendo and Kopeinig (2008) among others.
} 
In the next step we estimate the average treatment effects on the treated as depicted in Equation 2. In order to increase efficiency and being able to apply bootstrapping for inference we use a kernel matching algorithm. ${ }^{12}$ To assess the matching quality, that is, whether the matching procedure balances the distribution of observable variables between participants and non-participants, Table A.3 summarizes different quality measures. ${ }^{13}$ First of all, we provide in the upper part the number of variables which differ significantly between participants and non-participants by using a $t$-test. ${ }^{14}$ For instance, we can see that for SUS, 28 variables have a mean that is significantly different between treated and nontreated at the $5 \%$ level before matching takes place. In the matched sample in turn, only two variables are significantly different for treated and non-treated individuals. In fact, in the case of BA after matching, we find no significant differences at all. This indicates that matching has been successful. Since using a $t$-test to assess the matching quality does not tell us anything about the bias reduction, we also provide the mean standardized bias (MSB) and the number of variables with a standardized bias of a certain amount. It can be seen that in case of "SUS vs. NP" ("BA vs. NP") the MSB declines from initially $14.6 \%$ to $3.5 \%$ ( $8.6 \%$ to $2.2 \%$ ) after matching, where a MSB below $3 \%$ to $5 \%$ generally indicates a success of the matching approach (Caliendo and Kopeinig, 2008). Finally, we also re-estimate the propensity scores within the matched sample, as suggested by Sianesi (2004). The distribution of covariates should be well balanced within the matched sample and hence the resulting pseudo- $R^{2}$ from the propensity score estimation should be rather low. In fact, we do observe a sharp drop in pseudo- $R^{2}$ for both programs also suggesting a successful matching.

\section{Results}

The aim of the programs is to integrate unemployed individuals in the labor market and to increase income levels. Therefore, we use different outcome variables for the calculation of causal effects. We employ "not unemployed" and "self-employed or regularly employed" as binary outcome variables to measure the degree of labor market integration. This is due to two reasons. First, non-participants are less likely to become self-employed than participants; and hence, comparing participants and non-participants with respect to selfemployment only would bias the causal effects upwards. Second, the main objective of ALMP is to integrate individuals into the labor market which includes being regularly employed as a success. We also want to highlight that being not registered as unemployed captures an upper bound estimation for the degree of labor market integration, i.e., independence of unemployment or social benefits. The binary outcome variables take on

\footnotetext{
${ }^{12}$ More specifically, we apply an Epanechnikov Kernel with an bandwidth of 0.06 . We run different matching algorithm and find that our results are not sensitive. Furthermore, we applied inverse probability weighting (IPW) as an alternative approach for estimating ATT, as suggested by Imbens (2004). This method also relies on the CIA. Using IPW, we find hardly any substantial differences for the employment effects but slightly higher income effects.

${ }^{13}$ For a more intensive discussion with respect to assessing the matching quality, we refer to Caliendo and Kopeinig (2008).

${ }^{14} \mathrm{We}$ consider the distribution of observable characteristics between participants and non-participants before and after matching based on 56 variables in total.
} 
the value one if the individual is either "not unemployed" or "self-employed or regularly employed" and zero otherwise. Moreover, we use "working income" and "total income" as continuous outcome variables to figure out whether program participation leads to an increase in income levels.

In the following, we first discuss the causal effects of SUS and BA with respect to the predefined outcome variables in Section 4.1. Afterwards, we consider effect heterogeneity in Section 4.2 to investigate for which subgroups both programs are in particular successful. Finally, Section 4.3 verifies the validity of our results with respect to unobserved heterogeneity.

\subsection{Main Results}

Figure 1 shows the average treatment effect on the treated as defined in Equation 2 over time and Table 6 provides the corresponding exact values for selected points in time. As one can see in Figure 1, the effects are positive and significant at all times for either outcome variable. To be precise, 56 months after start-up, participants in SUS (BA) have a $15.6 \%(10.6 \%)$ higher probability of not being registered as unemployed compared to non-participants. Regarding integration into the labor market, that is being either selfemployed or regularly employed, we detect that the employment probability of participants is 22.1 percentage points higher for SUS and 14.5 percentage points for BA participants in comparison to non-participants. These strong positive long-run effects are remarkable compared to findings of evaluation studies investigating other programs of ALMP in Germany, such as vocational training or job creation schemes.

\section{InSERT Figure 1 ABOUt HeRE}

Moreover, for BA the positive effect seems to be rather stable after three years following start-up, indicating that either surviving firms or employed individuals are well integrated in the (labor) market. For individuals supported with SUS, we do not find such a convergence. We argue that due to financial support which lasted longer, the adjustment process at the market is still ongoing. Because of this and the fact that the control group for BA participants is more competitive in the labor market than the assigned control group for SUS participants, the higher effects for SUS can not be directly contrasted to the results of BA participants. In Table 6, we also provide the cumulated effects over time which reveal that within our observation period of 56 months, participants in SUS (BA) spent on average 23.5 (14.6) months more in self-employment or regular employment than non-participants. One may argue that cumulating the effects over the entire period will capture locking-in effects and lead to an overestimation of the effects, since participants received financial support. We take care of this by providing "partly" cumulated effects, for which we cumulate the effects only over the period after financial support ended. For the case of SUS, we find that participants are still on average 5.5 months longer self-employed or regularly employed than non-participants which actually depicts $20 \%$ of the post-program period of 20 months. For BA participants, we find a partly cumulated effect of 10.8 months, which is also $20 \%$ of the remaining period (of 50 
months in this case). To shed light on the question of income gains for participants, we provide the causal effects for income differences at the end of the observation period at the bottom of Table 6 . The results unambiguously show that participants earn significantly more than non-participants. Participants in SUS (BA) earn on average, $€ 435$ (€618) more per month than non-participants at the end of our observation period. When compared to the monthly net income of participants and non-participants (see again Table 4) these are economically very significant effects.

\section{INSERT TABLE 6 ABOUt HERE}

In addition to our matching results, Table 6 also provides the cumulated employment and income effects for the conditional DID estimator as defined in Equation 4. As we can see the results hardly differ. For instance, for the case of "BA vs. NP" we find participants being on average 14.6 months longer in employment or self-employment than non-participants using the total cumulated effect. Using conditional DID, the results vary from 14.1 to 14.6. The income effects are also very close to the matching results. This evidence indicates that controlling for time-invariant unobserved heterogeneity does not add essential information and consequently suggests that the CIA seems to be a reasonable assumption for our analysis. We also estimated the optimal subpopulation average treatment effects (OSATE) as suggested by Crump, Hotz, Imbens, and Mitnik (2009) where we restrict the analysis to a subset of the original sample and drop individuals with covariate values that are outside the optimal common support range. We do not find any significant differences to our main results. ${ }^{15}$

In summary, our results suggest that supporting unemployed individuals by SUS or BA has been a success in terms of both employment prospects as well as income measures compared to non-participation.

\subsection{Effects for Subgroups: Effect Heterogeneity}

In the following, we take a closer look on effect heterogeneity. This is in particularly insightful when determining the type of individuals who benefit most from participation. Disadvantaged groups in the labor market, such as low educated or young individuals, are likely to face limited job offers and the opportunity of becoming self-employed depicts a chance to escape unemployment. Additionally, self-employment might also be an alternative for individuals who are potentially discriminated in dependent employment, for example if their work is not valued high enough (see Clark and Drinkwater, 2000, for some evidence regarding ethnic minorties in the UK). We also have to take into account, that more educated unemployed individuals with past working experience have a relatively high probability of finding dependent employment again. Therefore, the distance between participants and matched non-participants in terms of labor market perspectives should be rather small. Taken together, this leads us to expect that the net effects of start-up programs (when compared to non-participation) are highest for disadvantaged individuals.

\footnotetext{
${ }^{15}$ Restricting the estimation sample in such a way lowers external validity of the estimate, but probably enhances internal validity (Imbens and Wooldridge, 2008). Results are available upon request from the authors.
} 
To answer the question of who benefits most, we conduct the complete estimation procedure, that is propensity score estimation and kernel-matching, for different subgroups of our sample with respect to educational attainment, professional qualification, age and nationality. The results are summarized in Table A.4, in which the upper part depicts the effects for the whole sample.

First of all, consider the results stratified by educational attainment. We split the sample into high (completed upper secondary school) and low (no degree, lower or middle secondary school) educated individuals. It can be seen that low educated participants perform better in both programs in terms of employment prospects; the total cumulated effect is about 5 months larger than for high educated individuals. This is mainly driven by the fact that the control group of the highly educated have a higher probability of being employed at all times than the respective low educated comparison group. We illustrate that in Figure A.2 by showing the levels for the outcome variable "self-employment or regular employment" among participants and non-participants within the matched sample; the difference between the respective solid and dashed line corresponds to the ATT presented in Table A.4. This confirms our expectation that the low educated control group performs relatively worse and consequently the effects are bigger for that group. Hence, offering individuals with bad labor market prospects the opportunity to turn unemployment into self-employment can be considered an effective strategy. The income effects in Table A.4 do not reveal such obvious patterns. In the case of "SUS vs. NP" the low educated participants yield much higher income effects compared to non-participation than the highly educated do. For the comparison "BA vs. NP" it is the reverse, that is the highly educated are better off than their low educated counterparts. This suggests that highly educated BA recipients who survived in self-employment are also very successful in terms of income. Furthermore, we conduct a separate analysis for different levels of professional qualification. Here we define all individuals with tertiary or technical college education as highly qualified; whilst skilled or unskilled workers are low qualified. As we can see in Table A.4 the effect pattern is very similar to the one of educational attainment (because professional qualification and educational attainment are highly correlated).

We also conduct the analysis separately for individuals aged 30 or younger as well as for individuals above the age of 30 . Here, the employment effects of the two programs go in opposing directions. The results suggest that SUS tends to be more effective for participants above the age of 30; whereas BA seems to be more effective for younger participants. Figure A.2 reveals that this is again mainly due to different labor market performance of the respective control groups. For both programs, there is hardly any difference between the program participants, that is the solid lines almost overlap. However, in the case of SUS controls, a considerable higher share of young controls is employed or self-employed and the reverse applies for BA. Probably more experienced ( $>30$ years) BA controls are more likely to be employed or self-employed which seems reasonable given that BA attracts rather highly educated individuals with higher earnings in the past (see Section 3.1). Apparently, for these individuals experience is important in order to find a job in the labor market and therefore older BA control individuals perform better in the labor market. On the other hand, low educated individuals with bad labor market performance 
in the past (mainly attracted by SUS) have fewer opportunities in the labor market the older they are. The income effects are consistently higher for younger individuals.

Finally, we stratify the analysis with respect to German or non-German citizenship and find higher employment effects for natives. Figure A.2 shows that the higher effects for natives are driven by the success of the participants. It can be seen that control groups do not really differ for both groups. This in turn suggests that SUS and BA seem to be even more effective for German participants. Additionally, natives achieve higher income effects even though they are not significant for the SUS case.

\section{InSERT Figure 2 ABOUt HERE}

Figure 2 exemplifies our findings with respect to effect heterogeneity and depicts the effects of program participation conditional on labor market perspectives without program participation. Therefore, we contrast cumulated average treatment effects for the outcome variable "self-employment or regular employment" (horizontal axis) to the average months spent in "self-employment or regular employment" among matched nonparticipants (vertical axis), which is supposed to reflect the labor market perspectives in case of non-participation. The scatter plot clearly indicates a negative relationship, underscoring the finding that groups with bad labor market perspectives benefit most. For instance, for individuals with high education/high qualification the estimated effects (horizontal axis) of the programs are rather small, however, for the opposite case-low education/low qualification - the effects are large. This suggests that SUS and BA are most effective for particular disadvantaged groups who face limited options in dependent employment. As previously mentioned, such groups are at high risk of becoming long-term unemployed; and therefore, these ALMP programs potentially contribute to the reduction of long-term unemployment amongst disadvantaged unemployed.

\subsection{Sensitivity to Unobserved Heterogeneity}

After having presented strong positive effects for both programs, we now check the robustness of our results with respect to deviations from our identifying assumption. If participants and non-participants differ in terms of unobserved characteristics, the CIA is violated and therefore our results are biased. Using the DID estimator in Section 4.1 already relaxed the identifying assumption by allowing for time-invariant unobservable differences between both groups. Since it is not possible to test the CIA directly with non-experimental data; we now use a bounding approach initially suggested by Rosenbaum (2002). This approach consists of simulating an unobserved component and testing to which degree of unobserved heterogeneity results are robust. It should be clear that this approach does not answer the question whether or not the CIA is fulfilled but conveys information on the robustness of the results with respect to unobserved heterogeneity. The main idea is that in the presence of unobserved factors, identical individuals with respect to observable characteristics $\left(W_{i}\right)$ have different probabilities of receiving treatment. Therefore, an artificial factor $\Gamma$ is introduced to simulate an unobserved term. The 
underlying test statistic then tests up to which extent this unobserved factor $\Gamma$ will influence the significance of the results (see Becker and Caliendo, 2007, for more details on the implementation of the test procedure and the STATA module mhbounds.ado).

We find strong positive effects for both programs and therefore we are only interested in the test-statistic for the upper bound under the assumption that we have overestimated the treatment effect. In other words, if unobserved factors lead to positive selection, i.e., those who participate always have a higher employment probability even in the absence of treatment, the test statistic $\mathrm{Q}^{+}$will become insignificant for a certain value of $\Gamma$. To ease the interpretation we also provide respective $\mathrm{p}$-values $\left(\mathrm{p}^{+}\right)$.

Table A.5 summarizes test statistics separately for the outcome variables "not unemployed" and "self-employment or regular employment" and for "SUS vs. NP" and "BA vs. NP." We consider the outcome variables after 36 months since start-up in the upper part of Table A.5 and after 56 months in the lower part. ${ }^{16}$ Below the detailed test-statistics and respective p-values we provide the exact values of $\Gamma$ at which results turn insignificant. First of all, in the case of the absence of unobserved heterogeneity, that is $\Gamma=1.0$, we can see that the test statistic for the upper bounds are significant throughout, indicated by $p^{+}<0.05$. Starting from that point, we stepwise increase the value of $\Gamma$. As mentioned above, this actually simulates an ascending influence of unobserved factors. For the comparison "BA vs. NP" results are very robust against strong unobserved selection bias; up to $\Gamma=3$ results remain significant. This implies that unobserved factors would need to have twice the influence (on selection and outcomes) as $W_{i}$ in order to undermine the results. For the comparison "SUS vs. NP" on the other hand, results are slightly more sensitive with critical values of 1.25 and 1.30 after 56 months. While this does not mean that there is unobserved heterogeneity influencing our results, this does call for a cautious interpretation of the results for SUS.

\section{Conclusion}

In this paper, we analyze the effects of two programs designed to turn unemployment into self-employment in West Germany. The programs differ in their design and attract different types of persons. Individuals participating in the bridging allowance are more educated and have higher earnings in the past; whereas SUS participants are on average less educated and have a relatively poor previous labor market performance. Using an unique data set consisting of administrative and survey data, we are able to add two substantial aspects to previous literature: First of all, we observe individuals for nearly five years following start-up, such that we are able to provide first evidence on the longterm effects of these programs (especially for industrialized countries). Second, we carefully consider effect heterogeneity in order to determine for which groups programs work best.

We base our analysis on conditional propensity score matching methods to assess the effectiveness of SUS and BA against non-participation. In particular, we use the probability of being employed (either self-employed or as an employee) and personal income

\footnotetext{
${ }^{16} \mathrm{We}$ also conducted the test for different points in time but the results hardly differ.
} 
as outcome variables. The results show that both programs are effective with respect to employment probabilities. Participants in SUS (BA) spend significant amounts of time longer in employment or self-employment than non-participants. Our results also unambiguously show that participants earn significantly more than non-participants. To validate our findings, we conduct sensitivity checks with respect to unobserved heterogeneity and find that our results are robust. Additionally, self-employed participants are also more satisfied with their self-employment compared to previous dependent employment. Regarding effect heterogeneity, we estimate causal effects for different subgroups stratified by educational attainment, professional qualification, age and nationality. The results suggest that both programs are especially effective for low educated and low qualified individuals; with respect to nationality and age results are mixed.

Overall, we find persistent positive long-run effects of SUS and BA on the employment situation of former unemployed individuals. This is particularly true for individuals who are at high risk of being excluded from the labor market and becoming long-term unemployed. Following the concept of Sen (1997), SUS and BA helped abolish labor market barriers for disadvantaged groups and sustainably integrated those into the labor market. Potentially, both programs are appropriate for fighting long-term unemployment, social exclusion and therefore poverty.

However, we also need to point out some limitations of our study and outline further research needed. First of all, it needs to be emphasized that we do a partial-equilibrium analysis focussing on the effects for participating individuals. Any general equilibrium or macroeconomic impacts can not be considered in this setting. This is especially true for substitution effects and crowding-out effects. Hence, our positive findings (on an individual level) need to be verified on a macroeconomic level in order to judge the scope of the programs to generate any positive macro effects. Second, it has often been argued that individuals who participate in start-up programs and become self-employed have characteristics (observed and/or unobserved) which make them different from other unemployed individuals. We address the selection issue by relying on a very informative dataset and applying conditional propensity score matching methods. This takes care for selection on observable and time-invariant unobservable characteristics. Additionally, we test the sensitivity of our results with respect to deviations from the identifying assumptions using a bounding approach and results turn out to be robust. Clearly, if there is any unobserved selection on top of this, which we are not able to pick up, we have an upward bias in the estimated treatment effects. Finally, it should also be clear that the data at hand does not allow to compare subsidized start-ups out of unemployment with other start-ups. To do so, we would need information on "regular" start-ups (unsubsidized, out of employment). This is one area of further research as is the question which of the two programs performs better. To analyze the latter, participants in both programs need to be compared directly which would also allow to reveal the scope of additional job creation by subsidized firms. Finally, investigating the effects for groups neglected here-women and the East German labor market - will allow to give a more complete picture of the performance of these two programs. 


\section{References}

Almeida, R., and E. Galasso (2007): "Jump-Starting Self-Employment? Evidence Among Welfare Participants in Argentina," Discussion Paper 2902, IZA.

Baumgartner, H., and M. Caliendo (2008): "Turning Unemployment into SelfEmployment: Effectiveness of Two Start-Up Programmes," Oxford Bulletin of Economics and Statistics, 70(3), 347-373.

Becker, S., And M. Caliendo (2007): "Sensitivity Analysis for Average Treatment Effects," Stata Journal, 7(1), 71-83.

Betcherman, G., K. Olivas, and A. Dar (2004): "Impacts of Active Labor Market Programs: New Evidence from Evaluations with Particular Attention to Developing and Transition Countries," Social Protection Discussion Paper Series No. 0402, The World Bank.

Blundell, R., L. Dearden, and B. Sianesi (2005): "Evaluating the Impact of Education on Earnings in the UK: Models, Methods and Results from the NCDS," Journal of the Royal Statistical Society, Series A, 168(3), 473-512.

Caliendo, M. (2009): "Income Support Systems, Labor Market Policies and Labor Supply: The German Experience," Discussion Paper 4665, IZA.

Caliendo, M., and R. Hujer (2006): "The Microeconometric Estimation of Treatment Effects - An Overview," Allgemeines Statistisches Archiv, 90(1), 197-212.

Caliendo, M., R. Hujer, and S. Thomsen (2008): "The Employment Effects of Job Creation Schemes in Germany - A Microeconometric Evaluation," in Modelling and Evaluating Treatment Effects in Econometrics, ed. by D. L. Millimet, J. A. Smith, and E. Vytlacil, vol. 21 of Advances in Econometrics, pp. 381-428. Elsevier, Amsterdam.

Caliendo, M., and S. Kopeinig (2008): "Some Practical Guidance for the Implementation of Propensity Score Matching," Journal of Economic Surveys, 22(1), 31-72.

Caliendo, M., and A. Kritikos (2009): "Die reformierte Existenzgründungsförderung für Arbeitslose - Chancen und Risiken," Perspektiven der Wirtschaftspolitik, 10(2), 189213.

Card, D., J. Kluve, And A. Weber (2009): "Active Labor Market Policy Evaluations: A Meta-Analysis," Discussion Paper 4002, IZA.

Carling, K., and L. Gustafson (1999): "Self-employment Grants vs. Subsidized Employment: Is there a Difference in the Re-unemployment Risk?," Working Paper 1999:6, IFAU - Institute for Labour Market Policy Evaluation.

Clark, K., and S. Drinkwater (2000): "Pushed out or pulled in? Self-employment among ethnic minorities in England and Wales," Labour Economics, 7, 603-628.

Cressy, R. (1996): "Are Business Startups Debt-Rationed?," The Economic Journal, 106(438), 1253-1270.

Crump, R., V. J. Hotz, G. W. Imbens, and O. A. Mitnik (2009): "Dealing with Limited Overlap in Estimation of Average Treatment Effects," Biometrika, 96(1), 187199.

Cueto, B., And J. Mato (2006): "An Analysis of Self-Employment Subsidies with Duration Models," Applied Economics, 38, 23-32.

DAR, A., ANd I. S. Gill (1998): "Evaluationg Retraining Programs in OECD Countries: Lessons Learned," The World Bank Research Observer, 13(1), 79-101. 
Dar, A., and Z. Tzannatos (1999): "Active Labor Market Programs: A Review of the Evidence from Evaluations," SP Discussion Paper 9901, The World Bank.

Dunn, T., And D. Holtz-Eakin (2000): "Financial Capital, Human Capital, and the Transition to Self-Employment: Evidence from Intergenerational Links," Journal of Labor Economics, 18(2), 282-305.

FAY, R. (1996): "Enhancing the Effectiveness of Active Labor Market Policies: Evidence from Programme Evaluations in OECD Countries," Labour Market and Social Policy Occasional Papers 18, OECD.

Federal Employment Agency (various issues): Arbeitsmarkt. Nuremberg.

Fitzenberger, B., A. Osikominu, and R. Völter (2008): "Get Training or Wait? Long-Run Employment Effects of Training Programs for the Unemployed in West Germany," forthcoming in: Annales d'Èconomie et de Statistique.

Fritsch, M. (2008): "How does New Business Development Affect Regional Development? Introduction to the Special Issue," Small Business Economics, 30, 1-14.

Heckman, J., H. Ichimura, J. Smith, and P. Todd (1998): "Characterizing Selection Bias Using Experimental Data," Econometrica, 66(5), 1017-1098.

Heckman, J., R. LaLonde, and J. Smith (1999): "The Economics and Econometrics of Active Labor Market Programs," in Handbook of Labor Economics Vol.IIIA, ed. by O. Ashenfelter, and D. Card, pp. 1865-2097. Elsevier, Amsterdam.

Imbens, G. (2004): "Nonparametric Estimation of Average Treatment Effects under Exogeneity: A Review," The Review of Economics and Statistics, 86(1), 4-29.

ImBens, G., AND J. M. Wooldridge (2008): "Recent Developments in the Econometrics of Program Evaluation," Discussion Paper 3640, IZA.

Kelly, R., P. Lewis, C. Mulvey, and B. Dalzell (2002): "A Study to Better Assess the Outcomes in the New Enterprise Incentive Scheme: Report Prepared for the Department of Employment and Work Place Relations," , University of Western Australia, the Centre for Labour Market Research.

Kluve, J., And C. M. Schmidt (2002): "Can Training and Employment Subsidies Combat European Unemploment?," Economic Policy, 17(35), 409-448.

Lechner, M., R. Miquel, and C. Wunsch (2004): "Long-Run Effects of Public Sector Sponsored Training in West Germany," Discussion Paper No. 1443, IZA, Bonn.

Lechner, M., And C. Wunsch (2008): "What Did All the Money Do? On the General Ineffectiveness of Recent West German Labour Market Programmes," Kyklos, 61(1), $134-174$.

Martin, P., And D. Grubb (2001): "What Works and for Whom: A Review of OECD Countries Experiences with Active Labour Market Policies," Swedish Economic Policy Review, 8, 9-56.

Meager, M., P. Bates, and M. Cowling (2003): "An Evaluation of Business Start-Up Support for Young People," National Institute Economic Review, 186, 59-72.

Meager, N. (1993): "Self-employment and Labour Market Policy in the European Community," Discussion Paper FS I 93-201, WZB.

OECD (2008): Growing Unequal? Income Distribution and Poverty in OECD Countries. OECD.

(2009): Employment Outlook: Tackling the Jobs Crisis. Paris. 
O'Leary, C. J. (1999): "Promoting Self Employment Among the Unemployed in Hungary and Poland," Working Paper, W.E. Upjohn Institute for Employment Research.

Perry, G. (2006): "Are Business Start-Up Subsidies Effective for the Unemployed: Evaluation of Enterprise Allowance," Working paper, Auckland University of Technology.

Pfeiffer, F., And F. Reize (2000): "Business Start-Ups by the Unemployed - an Econometric Analysis Based on Firm Data," Labour Economics, 7, 629-663.

Rodriguez-Planas, N. (2008): "Channels Through Which Public Employment Services and Small-Business Assistance Programs Work," forthcoming in: Oxford Bulletin of Economics and Statistics.

Rosenbaum, P., And D. Rubin (1983): "The Central Role of the Propensity Score in Observational Studies for Causal Effects," Biometrika, 70(1), 41-50.

Rosenbaum, P. R. (2002): Observational Studies. Springer, New York.

Roy, A. (1951): "Some Thoughts on the Distribution of Earnings," Oxford Economic Papers, 3(2), 135-145.

Rubin, D. (1974): "Estimating Causal Effects to Treatments in Randomised and Nonrandomised Studies," Journal of Educational Psychology, 66, 688-701.

SEN, A. (1997): "Inequality, Unemploment and Contemporary Europe," International Labour Review, 136(2), 155-172.

SiAnesi, B. (2004): "An Evaluation of the Swedish System of Active Labour Market Programmes in the 1990s," The Review of Economics and Statistics, 86(1), 133-155.

Smith, J., And P. Todd (2005): "Does Matching Overcome LaLonde's Critique of Nonexperimental Estimators?," Journal of Econometrics, 125(1-2), 305-353.

Stephan, G. (2008): "The Effects of Active Labor Market Programs in Germany: An Investigation Using Different Definitions of Non-Treatment," Journal of Economics and Statistics, 228(5+6), 586-611.

Stephan, G., And A. Pahnke (2008): "A Pairwise Comparison of the Effectiveness of Selected Active Labour Market Programmes in Germany," Discussion Paper 29/2008, IAB.

Storey, D. (1994): Understanding the Small Business Sector. Routledge, London.

Wooldridge, J. M. (2002): Econometric Analysis of Cross Section and Panel Data. The MIT Press. 


\section{Tables and Figures}

Table 1: Terms and Conditions of Programs

\begin{tabular}{|c|c|c|}
\hline & Start-up Subsidy & Bridging Allowance \\
\hline Entry conditions: & $\begin{array}{l}\text {-Unemployment benefit receipt } \\
\text {-Income is restricted to } € 25,000 \text { per } \\
\text { year } \\
\text {-Approval of a business plan was } \\
\text { subsequently introduced in Novem- } \\
\text { ber } 2004 \\
\text {-Below } 65 \text { years of age }\end{array}$ & $\begin{array}{l}\text {-Unemployment benefit entitlement } \\
\text {-No income restrictions } \\
\text {-Approval of the business plan } \\
\text {-Below } 65 \text { years of age }\end{array}$ \\
\hline Support: & $\begin{array}{l}\text {-Participants receive a fixed sum of } \\
€ 600 \text { in the first year, } € 360(€ 240) \\
\text { in the second (third) year } \\
\text {-Claim has to be renewed every year }\end{array}$ & $\begin{array}{l}\text {-Participants receive UB for six } \\
\text { months } \\
\text {-To cover social security liabilities, } \\
\text { an additional lump sum of } 68.5 \% \text { is } \\
\text { granted }\end{array}$ \\
\hline Others: & $\begin{array}{l}\text {-Participants have to become a } \\
\text { member in the state pension insur- } \\
\text { ance and take advantage of a re- } \\
\text { duced rate in the legal health insur- } \\
\text { ance }\end{array}$ & $\begin{array}{l}\text {-Social security is left to the indi- } \\
\text { vidual's discretion }\end{array}$ \\
\hline
\end{tabular}

Source: Social Act III, §57 - Bridging Allowance, §421I - Start-up Subsidy.

Table 2: Entries into ALMP Programs in West Germany (in thousands)

\begin{tabular}{rrrrrrr}
\hline \hline & BA & SUS & New SUS & VT & TM & WS \\
\hline 2000 & 92.6 & - & - & 337.9 & 285.9 & 120.4 \\
2001 & 64.5 & - & - & 261.2 & 338.5 & 101.0 \\
2002 & 89.0 & - & - & 273.2 & 545.4 & 114.4 \\
2003 & 114.4 & 64.2 & - & 154.0 & 694.3 & 96.5 \\
2004 & 137.3 & 113.8 & - & 124.0 & 788.5 & 93.9 \\
2005 & 120.0 & 57.3 & - & 91.1 & 607.2 & 86.0 \\
2006 & 83.6 & 27.0 & 25.4 & 173.0 & 671.1 & 152.1 \\
2007 & - & - & 96.5 & 246.2 & 719.1 & 160.7 \\
& & & & & & \\
\hline
\end{tabular}

Source: Federal Employment Agency (various issues).

Note: BA - Bridging Allowance, SUS - Start-up Subsidy, VT

- Vocational Training, TM - Training Measures, WS - Wage Subsidy. 
Table 3: Number of Realized Interviews

\begin{tabular}{lrrr}
\hline \hline & SUS & BA & NP \\
\hline January/February 2005 & 1,116 & 1,665 & 2,530 \\
January/February 2006 & 811 & 1,207 & 1,448 \\
May/June 2008 & 486 & 780 & 929 \\
\hline \hline
\end{tabular}

Note: See Baumgartner and Caliendo (2008) for more details on the construction of the data and detailed information with respect to the first and second interview waves. A minor part of the third wave interviews (4\%) took place in July 2008.

Table 4: Descriptive Evidence on Labor Market Status and Income

\begin{tabular}{|c|c|c|c|}
\hline & Start-up Subsidy & Bridging Allowance & Non-Participants \\
\hline \multicolumn{4}{|l|}{ Labor market status } \\
\hline \multicolumn{4}{|c|}{ 2nd interview (January/February 2006) } \\
\hline Self-employed & 67.6 & 71.5 & 12.7 \\
\hline Regularly employed & 11.7 & 14.0 & 35.9 \\
\hline Unemployed or in ALMP & 15.2 & 11.1 & 35.9 \\
\hline Others & 5.6 & 3.4 & 15.5 \\
\hline \multicolumn{4}{|l|}{ 3rd interview (May/June 2008) } \\
\hline Self-employed & 59.7 & 67.9 & 14.1 \\
\hline Regularly employed & 20.9 & 21.1 & 49.1 \\
\hline Unemployed or in ALMP & 11.7 & 6.7 & 19.9 \\
\hline Others & 7.6 & 4.3 & 16.9 \\
\hline \multicolumn{4}{|c|}{ Income $^{a)}$ at $3 r d$ interview (May/June 2008) } \\
\hline \multirow[t]{3}{*}{ Total income } & $1,672.0$ & $2,336.0$ & $1,581.1$ \\
\hline & $(1,720.4)$ & $(1,962.9)$ & $(1,601.6)$ \\
\hline & {$[1,276.3]$} & {$[1,942.3]$} & {$[1,338.0]$} \\
\hline \multirow[t]{3}{*}{ Working income } & $1,498.5$ & $2,167.4$ & $1,302.8$ \\
\hline & $(1,780.2)$ & $(2,006.3)$ & $(1,662.5)$ \\
\hline & {$[1,145.3]$} & {$[1,815.2]$} & {$[1,190.1]$} \\
\hline
\end{tabular}

Note: Numbers are percentages unless otherwise stated.

a) Income is depicted as average monthly net income in euros; standard deviation and median are provided in parentheses and square brackets respectively.

Table 5: Comparison to Previous Dependent Employment

\begin{tabular}{lrr}
\hline \hline & Start-up Subsidy & Bridging Allowance \\
\hline Type of activity & 0.6 & 0.5 \\
Income & 0.2 & 0.2 \\
Promotion prospects & 0.5 & 0.5 \\
Workload & -0.1 & -0.1 \\
Working time & -0.2 & -0.3 \\
Social security & -0.2 & -0.3 \\
\hline
\end{tabular}

Note: Only self-employed individuals after 56 months since start-up. Scale: Improved (1), Unchanged (0), Declined (-1). 
Table 6: Causal Effects of Start-up Subsidy and Bridging Allowance

\begin{tabular}{lrr}
\hline \hline & $\begin{array}{c}\text { Start-up Subsidy vs. } \\
\text { Non-Participation }\end{array}$ & $\begin{array}{c}\text { Bridging Allowance vs. } \\
\text { Non-Participants }\end{array}$ \\
\hline \multicolumn{2}{c}{ Outcome variable: "Not unemployed" } \\
Difference in percentage points & $59.4(3.0)$ & $49.3(2.8)$ \\
After 6 months & $22.9(3.4)$ & $10.9(1.8)$ \\
After 36 months & $15.6(2.9)$ & $10.6(1.8)$ \\
After 56 months & & $12.2(0.8)$ \\
Difference in months & $18.7(1.3)$ & $12.2(0.8)$ \\
Total cumulated effect $\left(\sum_{t=1}^{56}\right)$ & $17.7(1.2)$ & $11.7(0.7)$ \\
DID1 & $17.9(1.3)$ & $11.7(0.7)$ \\
DID2 & $16.9(1.5)$ & $8.5(0.7)$ \\
DID3 & $3.9(0.6)$ & $8.5(0.7)$ \\
Partly cumulated effect ${ }^{a)}$ & $2.9(0.7)$ & $8.0(0.7)$ \\
DID1 & $3.1(0.8)$ & $8.0(0.7)$ \\
DID2 & $2.1(1.2)$ & \\
DID3 &
\end{tabular}

Outcome variable: "Self-employment or regular employment"

Difference in percentage points

$\begin{array}{lrr}\text { After } 6 \text { months } & 68.5(2.6) & 55.0(2.5) \\ \text { After } 36 \text { months } & 29.4(3.3) & 15.3(2.1) \\ \text { After } 56 \text { months } & 22.1(3.4) & 14.5(1.9) \\ \text { Difference in months } & & \\ \text { Total cumulated effect }\left(\sum_{t=1}^{56}\right) & 23.5(1.3) & 14.6(0.9) \\ \text { DID1 } & 22.6(1.3) & 14.6(0.9) \\ \text { DID2 } & 22.7(1.4) & 14.1(0.9) \\ \text { DID3 } & 21.7(1.4) & 14.1(0.9) \\ \left.\text { Partly cumulated effect }{ }^{a}\right) & 5.5(0.6) & 10.8(0.9) \\ \text { DID1 } & 4.5(0.8) & 10.8(0.8) \\ \text { DID2 } & 4.6(0.7) & 10.2(0.9) \\ \text { DID3 } & 3.7(1.0) & 10.2(0.8)\end{array}$

Outcome variable: "Income 56 months after start-up"

Difference in $€ /$ month

Working income

DID4

$435(135)$

$475(130)$

$618(110)$

Total income

$270(121)$

$656(128)$

DID5

$288(139)$

$485(110)$

$480(128)$

Note: Depicted are average treatment effects on the treated as the difference in outcome variables between participants and non-participants. Standard errors are in parentheses and are based on bootstrapping with 200 replications.

Reference level for pre-treatment period: DID1: Jan. 2001 - June 2003; DID2: July 1998

- Dec. 2000; DID3: July 1998 - June 2003; DID4: average monthly total income in 2002;

DID5: average monthly income from employment in 2002.

a) SUS: $\sum_{t=37}^{56}, \mathrm{BA}: \sum_{t=7}^{56}$ 
Figure 1: Causal Effects of Start-up Subsidy and Bridging Allowance Over Time

Outcome variable: "Not unemployed"

Start-up Subsidy vs. Non-Participation

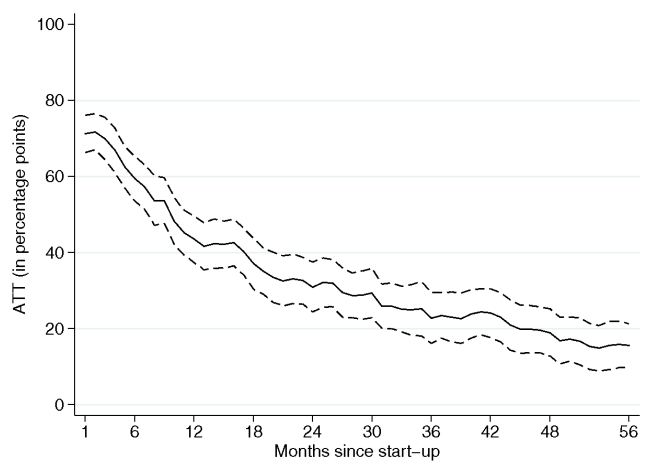

Bridging Allowance vs. Non-Participation

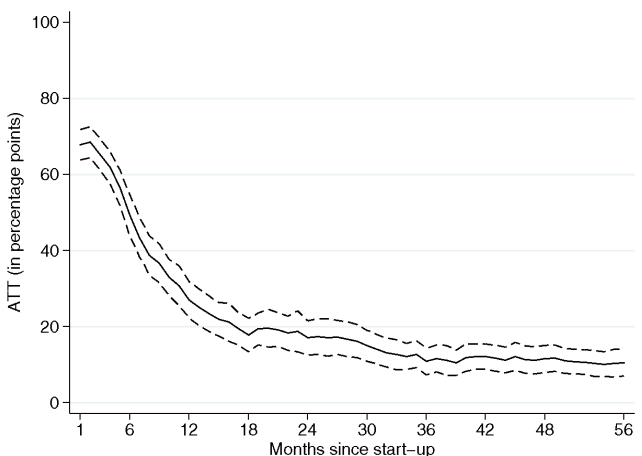

Outcome variable: "Self-employment or regular employment"

Start-up Subsidy vs. Non-Participation

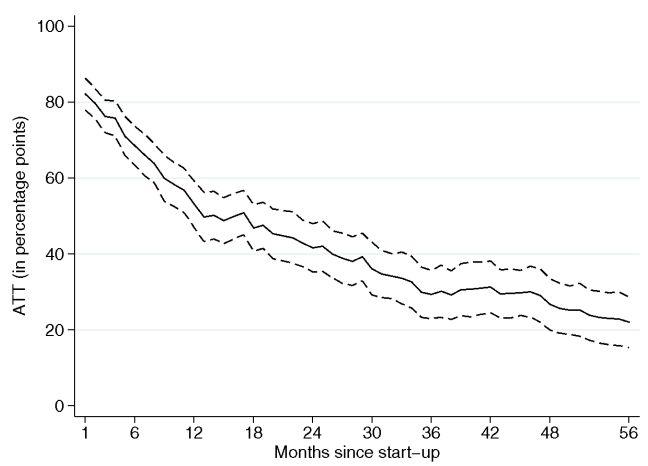

Bridging Allowance vs. Non-Participation

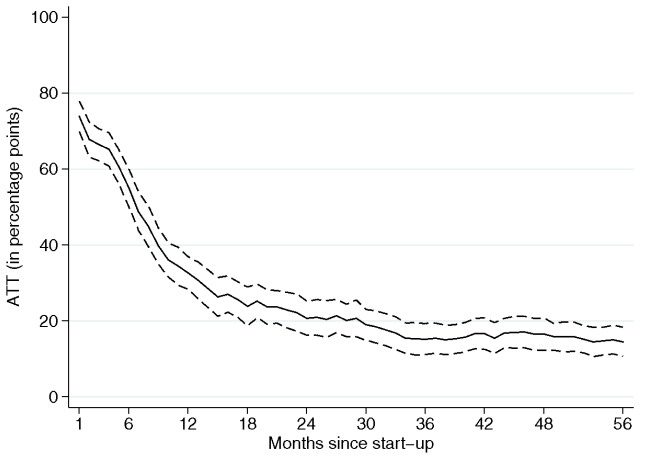

Note: Depicted are average treatment effects on the treated (solid line), i.e., the difference in outcome variables between participants and non-participants. In addition, we provide $5 \%$ confidence intervals (dashed lines), which are based on bootstrapped standard errors with 200 replications. 
Figure 2: Effect Heterogeneity Conditional on Labor Market Perspectives Among Matched Non-Participants

Outcome variable: "Self-employment or regular employment"

Start-up Subsidy

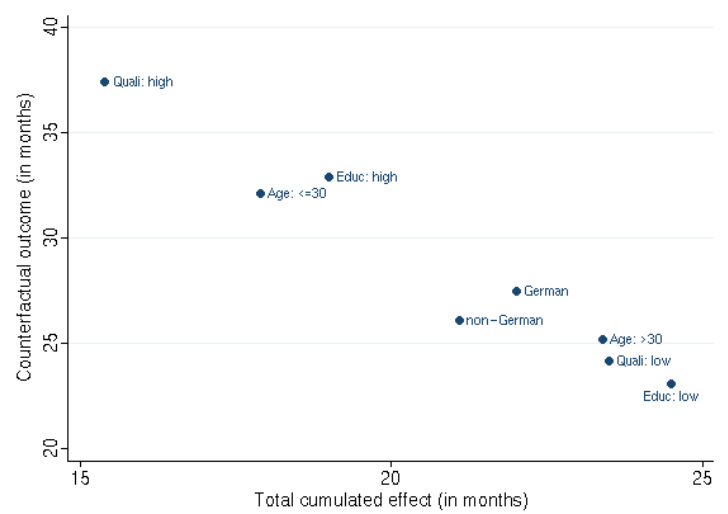

Bridging Allowance

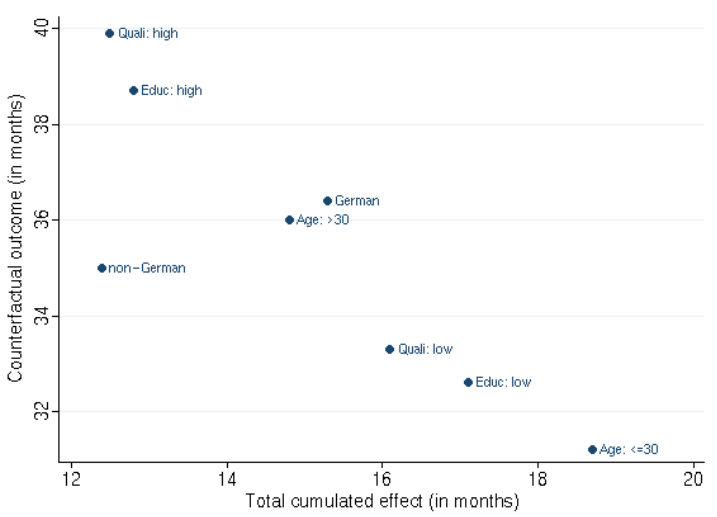

Note: Depicted on the horizontal axis are the cumulated average treatment effects on the treated consistent to Table A.4 for the outcome variable "self-employment or regular employment". On the vertical axis we provide the average months spent in "self-employment or regular employment" within the observation period of 56 months for the matched non-participants. 


\section{A Supplementary Appendix}

Table A.1: Selected Descriptive Statistics

\begin{tabular}{|c|c|c|c|}
\hline & $\begin{array}{l}\text { Start-up } \\
\text { Subsidy }\end{array}$ & $\begin{array}{l}\text { Bridging } \\
\text { Allowance }\end{array}$ & $\begin{array}{c}\text { Non- } \\
\text { Participants }\end{array}$ \\
\hline Number of observations ${ }^{a}$ ) & 472 & 756 & 853 \\
\hline Age (in years) & $\begin{array}{c}38.86 \\
(9.78)\end{array}$ & $\begin{array}{r}40.17 \\
(8.66)\end{array}$ & $\begin{array}{r}39.75 \\
(8.88)\end{array}$ \\
\hline \multicolumn{4}{|l|}{ Age bracket } \\
\hline 18 to 24 years & 0.068 & 0.026 & 0.049 \\
\hline 25 to 29 years & 0.131 & 0.095 & 0.095 \\
\hline 30 to 34 years & 0.174 & 0.126 & 0.130 \\
\hline 35 to 39 years & 0.153 & 0.242 & 0.212 \\
\hline 40 to 44 years & 0.176 & 0.200 & 0.210 \\
\hline 45 to 49 years & 0.127 & 0.160 & 0.165 \\
\hline 50 to 64 years & 0.172 & 0.151 & 0.138 \\
\hline \multicolumn{4}{|l|}{ Marital status (Ref.: Single) } \\
\hline Married & 0.472 & 0.648 & 0.594 \\
\hline \multicolumn{4}{|l|}{ Number of children in household } \\
\hline No children & 0.708 & 0.595 & 0.639 \\
\hline 1 child & 0.144 & 0.155 & 0.145 \\
\hline 2 or more children & 0.148 & 0.250 & 0.216 \\
\hline \multicolumn{4}{|c|}{ Health restriction that affect job placement (Ref.: No) } \\
\hline Yes & 0.078 & 0.033 & 0.057 \\
\hline \multicolumn{4}{|l|}{ Nationality (Ref.: German) } \\
\hline Non-German & 0.328 & 0.265 & 0.249 \\
\hline \multicolumn{4}{|l|}{ Desired working time (Ref.: Part-time) } \\
\hline Full-time & 0.977 & 0.992 & 0.984 \\
\hline \multicolumn{4}{|l|}{ School achievement } \\
\hline None & 0.028 & 0.007 & 0.014 \\
\hline Lower secondary school & 0.405 & 0.290 & 0.370 \\
\hline Middle secondary school & 0.250 & 0.233 & 0.223 \\
\hline Specialized upper secondary school & 0.104 & 0.193 & 0.150 \\
\hline Upper secondary school & 0.214 & 0.278 & 0.243 \\
\hline \multicolumn{4}{|l|}{ Occupational group } \\
\hline Manufacturing & 0.040 & 0.011 & 0.018 \\
\hline Agriculture & 0.333 & 0.233 & 0.277 \\
\hline Technical occupations & 0.038 & 0.160 & 0.108 \\
\hline Services & 0.517 & 0.565 & 0.539 \\
\hline Others & 0.072 & 0.032 & 0.059 \\
\hline \multicolumn{4}{|l|}{ Professional qualification } \\
\hline Workers with tertiary education & 0.123 & 0.259 & 0.200 \\
\hline Workers with technical college education & 0.068 & 0.112 & 0.106 \\
\hline Skilled workers & 0.559 & 0.515 & 0.549 \\
\hline Unskilled workers & 0.250 & 0.114 & 0.145 \\
\hline \multicolumn{4}{|l|}{ Duration of previous unemployment } \\
\hline$<1$ month & 0.133 & 0.074 & 0.014 \\
\hline$\geq 1$ month $-<3$ months & 0.150 & 0.222 & 0.223 \\
\hline$\geq 3$ months $-<6$ months & 0.212 & 0.249 & 0.251 \\
\hline$\geq 6$ months $-<1$ year & 0.288 & 0.316 & 0.339 \\
\hline$\geq 1$ year $-<2$ years & 0.155 & 0.124 & 0.150 \\
\hline$\geq 2$ years & 0.061 & 0.015 & 0.023 \\
\hline \multicolumn{4}{|c|}{ Professional experience (Ref.: Without professional experience) } \\
\hline With professional experience & 0.824 & 0.860 & 0.877 \\
\hline
\end{tabular}


Table A.1 continued.

\begin{tabular}{|c|c|c|c|}
\hline & $\begin{array}{l}\text { Start-up } \\
\text { Subsidy }\end{array}$ & $\begin{array}{l}\text { Bridging } \\
\text { Allowance }\end{array}$ & $\begin{array}{c}\text { Non- } \\
\text { Participation }\end{array}$ \\
\hline \multirow[t]{2}{*}{ Duration of last employment (in months) } & 32.394 & 54.041 & 41.963 \\
\hline & $(40.987)$ & $(54.358)$ & $(49.076)$ \\
\hline \multirow[t]{2}{*}{ Number of placement offers } & 5.367 & 3.758 & 5.181 \\
\hline & $(8.563)$ & $(6.921)$ & $(7.664)$ \\
\hline \multirow[t]{2}{*}{ Daily income from regular employment in the first half of 2003 (in euros) } & 9.969 & 25.783 & 20.700 \\
\hline & $(21.571)$ & $(41.503)$ & $(34.970)$ \\
\hline \multirow{2}{*}{ Unemployment benefit level (in euros) } & 24.363 & 40.405 & 33.167 \\
\hline & $(11.436)$ & $(15.275)$ & $(14.322)$ \\
\hline \multirow[t]{2}{*}{ Remaining unemployment benefit entitlement (in months) } & 4.752 & 7.317 & 7.054 \\
\hline & $(5.759)$ & $(6.380)$ & $(6.397)$ \\
\hline \multicolumn{4}{|l|}{ Employment status before job-seeking } \\
\hline Employment & 0.591 & 0.782 & 0.769 \\
\hline Self-employed & 0.053 & 0.024 & 0.036 \\
\hline School attendance/never employed before/apprenticeship & 0.123 & 0.073 & 0.063 \\
\hline Unemployable & 0.083 & 0.042 & 0.059 \\
\hline Other, but employed at least once before & 0.131 & 0.070 & 0.066 \\
\hline Other & 0.019 & 0.009 & 0.007 \\
\hline \multicolumn{4}{|l|}{ Regional cluster } \\
\hline II a & 0.013 & 0.024 & 0.028 \\
\hline II b & 0.153 & 0.159 & 0.135 \\
\hline III a & 0.127 & 0.071 & 0.088 \\
\hline III b & 0.083 & 0.091 & 0.110 \\
\hline III c & 0.222 & 0.237 & 0.244 \\
\hline IV & 0.127 & 0.144 & 0.117 \\
\hline $\mathrm{V}$ a & 0.036 & 0.042 & 0.038 \\
\hline $\mathrm{Vb}$ & 0.165 & 0.148 & 0.176 \\
\hline $\mathrm{V} \mathrm{c}$ & 0.074 & 0.083 & 0.064 \\
\hline \multicolumn{4}{|l|}{ Intergenerational transmission } \\
\hline Parents are/were self-employed & 0.284 & 0.284 & 0.155 \\
\hline
\end{tabular}

Note: Numbers are percentages unless otherwise stated. Measured in the third quarter 2003; standard deviation in parentheses. a) Differences to realized interviews in Table 3 are due to missing information in the administrative data for some individuals. 
Table A.2: Propensity Score Estimation

\begin{tabular}{|c|c|c|}
\hline & $\begin{array}{l}\text { Start-up Subsidy vs. } \\
\text { Non-Participation }\end{array}$ & $\begin{array}{l}\text { Bridging Allowance vs. } \\
\text { Non-Participation }\end{array}$ \\
\hline \multicolumn{3}{|l|}{ Age bracket (Ref.: 18 to 24 years) } \\
\hline 25 to 29 years & $0.430^{* *}$ & $0.354^{*}$ \\
\hline 30 to 34 years & $0.508^{* *}$ & 0.254 \\
\hline 35 to 39 years & 0.266 & 0.291 \\
\hline 40 to 44 years & $0.361^{*}$ & 0.119 \\
\hline 45 to 49 years & $0.433^{* *}$ & 0.196 \\
\hline 50 to 64 years & $0.863^{* * *}$ & 0.316 \\
\hline \multicolumn{3}{|l|}{ Marital status (Ref.: Single } \\
\hline Married & -0.098 & 0.009 \\
\hline \multicolumn{3}{|l|}{ Number of children in household (Ref.: No children) } \\
\hline one child & 0.184 & -0.105 \\
\hline Two or more children & 0.089 & -0.160 \\
\hline \multicolumn{3}{|l|}{ Health restriction that affect job placement (Ref.: No) } \\
\hline Yes & -0.129 & -0.090 \\
\hline \multicolumn{3}{|l|}{ Nationality (Ref.: German) } \\
\hline Non-German & 0.095 & $0.164^{* *}$ \\
\hline \multicolumn{3}{|l|}{ Desired working time (Ref.: Part-time) } \\
\hline Full-time & -0.037 & 0.135 \\
\hline \multicolumn{3}{|l|}{ School achievement (Ref.: None) } \\
\hline Lower secondary school & -0.081 & 0.228 \\
\hline Middle secondary school & 0.069 & 0.293 \\
\hline Specialized upper secondary school & -0.063 & 0.333 \\
\hline Upper secondary school & 0.038 & 0.288 \\
\hline \multicolumn{3}{|l|}{ Occupational group (Ref.: Manufacturing) } \\
\hline Agriculture & -0.250 & 0.100 \\
\hline Technical occupations & $-0.705^{* *}$ & 0.261 \\
\hline Services & -0.395 & 0.089 \\
\hline Others & $-0.597^{* *}$ & -0.342 \\
\hline \multicolumn{3}{|l|}{ Professional qualification (Ref.: Workers with tertiary education) } \\
\hline Workers with technical college education & 0.126 & -0.038 \\
\hline Skilled workers & 0.071 & 0.042 \\
\hline Unskilled workers & 0.198 & 0.066 \\
\hline \multicolumn{3}{|l|}{ Duration of previous unemployment (Ref.: $<1$ month) } \\
\hline$\geq 1$ month -3 months & $-1.634^{* * *}$ & $-0.893^{* * *}$ \\
\hline$\geq 3$ months $-<6$ months & $-1.488^{* * *}$ & $-0.943^{* * *}$ \\
\hline$\geq 6$ months $-<1$ year & $-1.639^{* * *}$ & $-1.069^{* * *}$ \\
\hline$\geq 1$ year $-<2$ years & $-1.765^{* * *}$ & $-1.118^{* * *}$ \\
\hline$\geq 2$ years & $-1.316^{* * *}$ & $-1.145^{* * *}$ \\
\hline \multicolumn{3}{|l|}{ Professional experience (Ref.: without professional experience) } \\
\hline with professional experience & -0.123 & $-0.251^{* *}$ \\
\hline Duration of last employment (in months) & 0.001 & $0.002^{* *}$ \\
\hline Number of placement offers & -0.006 & $-0.010^{* *}$ \\
\hline Remaining unemployment benefit entitlement (in months) & $-0.028^{* * *}$ & $-0.024^{* * *}$ \\
\hline Unemployment benefit level (in euros) & $-0.029^{* * *}$ & $0.024^{* * *}$ \\
\hline Daily income from regular employment in the first half of 2003 (in euros) & -0.002 & $-0.002^{*}$ \\
\hline \multicolumn{3}{|l|}{ Employment status before job-seeking (Ref.: Employment) } \\
\hline Self-employed & 0.290 & $-0.373^{*}$ \\
\hline School attendance/never employed before/apprenticeship & $0.362^{* *}$ & 0.225 \\
\hline Unemployable & 0.197 & -0.072 \\
\hline Other, but employed at least once before & $0.458^{* * *}$ & $0.246^{*}$ \\
\hline Other & 0.352 & 0.456 \\
\hline
\end{tabular}

Table to be continued. 
Table A.2 continued.

\begin{tabular}{lcc}
\hline & $\begin{array}{c}\text { Start-up Subsidy vs. } \\
\text { Non-Participation }\end{array}$ & $\begin{array}{c}\text { Bridging Allowance vs. } \\
\text { Non-Participation }\end{array}$ \\
\hline Regional cluster (Ref.: II a) & $0.730^{* *}$ & 0.224 \\
II b & $0.744^{* *}$ & 0.043 \\
III a & $0.545^{*}$ & 0.157 \\
III b & $0.609^{*}$ & 0.118 \\
III c & $0.911^{* * *}$ & 0.183 \\
IV & $0.636^{*}$ & 0.415 \\
V a & $0.707^{* *}$ & -0.041 \\
V b & $0.782^{* *}$ & 0.262 \\
V c & & $0.453^{* * *}$ \\
Intergenerational transmission & $0.476^{* * *}$ & -0.607 \\
Parents are/were self-employed & $1.240^{* *}$ & \\
Constant & & 0.105 \\
\hline Number of observations & \multicolumn{2}{c}{872} \\
Participants & 853 & -995.964 \\
Non-Participants & 0.196 & \\
Pseudo R ${ }^{2}$ & -693.612 & \\
Log-likelihood & & \\
\hline \hline
\end{tabular}

Note: $* 10 \%, * * 5 \%, * * * 1 \%$ significance level.

Table A.3: Matching Quality

\begin{tabular}{|c|c|c|c|c|}
\hline & \multicolumn{2}{|c|}{ Start-up Subsidy } & \multicolumn{2}{|c|}{ Bridging Allowance } \\
\hline & Before matching & After matching & Before matching & After matching \\
\hline \multicolumn{5}{|l|}{ t-test of equal means ${ }^{a}$ ) } \\
\hline $1 \%$-level & 19 & 0 & 9 & 0 \\
\hline $5 \%$-level & 28 & 0 & 15 & 0 \\
\hline $10 \%$-level & 33 & 0 & 17 & 0 \\
\hline \multicolumn{5}{|l|}{ Standardized bias } \\
\hline Mean standardized bias & 14.550 & 3.539 & 8.565 & 2.194 \\
\hline \multicolumn{5}{|c|}{ Number of variables with standardized bias of a certain amount } \\
\hline$<1 \%$ & 2 & 12 & 3 & 22 \\
\hline $1 \%$ until $<3 \%$ & 4 & 14 & 11 & 18 \\
\hline $3 \%$ until $<5 \%$ & 4 & 14 & 6 & 7 \\
\hline $5 \%$ until $<10 \%$ & 15 & 15 & 21 & 9 \\
\hline$\geq 10 \%$ & 31 & 1 & 15 & 0 \\
\hline Pseudo- $\mathrm{R}^{2}$ & 0.196 & 0.013 & 0.105 & 0.007 \\
\hline
\end{tabular}

a) Depicted is the number of variables which differ significantly between treated and controls. The decision is based on a simple t-test of equal means. There are 56 observable variables in total. 
Table A.4: Effect Heterogeneity: Causal Effects of Start-up Subsidy and Bridging Allowance

\begin{tabular}{|c|c|c|c|c|}
\hline & \multicolumn{2}{|c|}{$\begin{array}{l}\text { Start-up Subsidy vs. } \\
\text { Non-Participation }\end{array}$} & \multicolumn{2}{|c|}{$\begin{array}{l}\text { Bridging Allowance vs. } \\
\text { Non-Participants }\end{array}$} \\
\hline & \multicolumn{4}{|c|}{ Main results } \\
\hline \# Treated & \multicolumn{2}{|c|}{472} & \multicolumn{2}{|c|}{756} \\
\hline \# Controls & \multicolumn{2}{|c|}{853} & \multicolumn{2}{|c|}{853} \\
\hline \multicolumn{5}{|l|}{ Self-employed or regularly employed } \\
\hline After 36 months (in \%-points) & \multicolumn{2}{|c|}{29.4} & \multicolumn{2}{|c|}{15.3} \\
\hline After 56 months (in \%-points) & \multicolumn{2}{|c|}{22.1} & \multicolumn{2}{|c|}{14.5} \\
\hline Total cumulated effect $\left(\sum_{t=1}^{56}\right.$, in months $)$ & \multicolumn{2}{|c|}{23.5} & \multicolumn{2}{|c|}{14.6} \\
\hline \multirow[t]{3}{*}{ Working income $(\mathrm{t}=56$, in $€ /$ month $)$} & \multicolumn{2}{|c|}{435} & \multicolumn{2}{|c|}{618} \\
\hline & \multicolumn{4}{|c|}{ Educational level } \\
\hline & Low & High & Low & High \\
\hline \# Treated & 322 & 150 & 400 & 356 \\
\hline \# Controls & 518 & 335 & 518 & 335 \\
\hline \multicolumn{5}{|l|}{ Self-employed or regularly employed } \\
\hline After 36 months (in \%-points) & 29.6 & 25.5 & 20.0 & 10.6 \\
\hline After 56 months (in \%-points) & 23.7 & 17.6 & 19.2 & 11.7 \\
\hline Total cumulated effect $\left(\sum_{t=1}^{56}\right.$, in months $)$ & 24.5 & 19.0 & 17.1 & 12.8 \\
\hline \multirow[t]{3}{*}{ Working income $(\mathrm{t}=56$, in $€ /$ month $)$} & 616 & $(-100)$ & 416 & 768 \\
\hline & \multicolumn{4}{|c|}{ Professional qualification } \\
\hline & Low & High & Low & High \\
\hline \# Treated & 382 & 90 & 475 & 281 \\
\hline \# Controls & 592 & 261 & 592 & 261 \\
\hline \multicolumn{5}{|l|}{ Self-employed or regularly employed } \\
\hline After 36 months (in \%-points) & 27.3 & 16.3 & 15.8 & 12.7 \\
\hline After 56 months (in \%-points) & 20.5 & 11.5 & 17.1 & 12.4 \\
\hline Total cumulated effect ( $\sum_{t=1}^{56}$, in months) & 23.5 & 15.4 & 16.1 & 12.5 \\
\hline \multirow[t]{3}{*}{ Working income $(\mathrm{t}=56$, in $€ /$ month $)$} & 628 & -464 & 486 & 865 \\
\hline & \multicolumn{4}{|c|}{ Age } \\
\hline & $\leq 30$ & $>30$ & $\leq 30$ & $>30$ \\
\hline \# Treated & 112 & 360 & 110 & 646 \\
\hline \# Controls & 141 & 712 & 141 & 712 \\
\hline \multicolumn{5}{|l|}{ Self-employed or regularly employed } \\
\hline After 36 months (in \%-points) & 21.9 & 27.0 & 20.1 & 15.7 \\
\hline After 56 months (in \%-points) & $(8.7)$ & 21.3 & 10.5 & 16.2 \\
\hline Total cumulated effect $\left(\sum_{t=1}^{56}\right.$, in months $)$ & 17.9 & 23.4 & 18.7 & 14.8 \\
\hline Working income $(\mathrm{t}=56$, in $€ /$ month $)$ & 543 & 374 & 914 & 573 \\
\hline
\end{tabular}

Table to be continued. 
Table A.4 continued.

\begin{tabular}{|c|c|c|c|c|}
\hline & \multicolumn{2}{|c|}{$\begin{array}{l}\text { Start-up Subsidy vs. } \\
\text { Non-Participation }\end{array}$} & \multicolumn{2}{|c|}{$\begin{array}{l}\text { Bridging Allowance vs. } \\
\text { Non-Participants }\end{array}$} \\
\hline & \multicolumn{4}{|c|}{ Nationality } \\
\hline & Native & Non-German & Native & Non-German \\
\hline \# Treated & 317 & 155 & 556 & 200 \\
\hline \# Controls & 641 & 212 & 641 & 261 \\
\hline \multicolumn{5}{|l|}{ Self-employed or regularly employed } \\
\hline After 36 months (in \%-points) & 27.3 & 20.6 & 15.9 & 10.6 \\
\hline After 56 months (in \%-points) & 20.0 & 15.7 & 14.2 & 14.5 \\
\hline Total cumulated effect $\left(\sum_{t=1}^{56}\right.$, in months $)$ & 22.0 & 21.1 & 15.3 & 12.4 \\
\hline Working income $(\mathrm{t}=56$, in $€ /$ month $)$ & $(305)$ & $(249)$ & 612 & 587 \\
\hline
\end{tabular}

Note: Depicted are average treatment effects on the treated as the difference in outcome variables between participants and non-participants. The educational level is decomposed into "high" education, capturing individuals who have successfully completed upper secondary school, and "low" education, including individuals who have either not completed school or have completed lower or middle secondary school. With respect to professional qualifications we define individuals with tertiary or technical college education as "highly" qualified, while skilled or unskilled workers are categorized as "low" qualified. Effects which are not significant different from zero at the 5\%-level are in parentheses; standard errors are based on bootstrapping with 200 replications.

Table A.5: Unobserved Heterogeneity: Mhbounds

\begin{tabular}{|c|c|c|c|c|c|c|c|c|}
\hline \multirow[t]{3}{*}{$\Gamma$} & \multicolumn{4}{|c|}{ Not-unemployed } & \multicolumn{4}{|c|}{ Self-employment or regular employment } \\
\hline & \multicolumn{2}{|c|}{ SUS vs. NP } & \multicolumn{2}{|c|}{ BA vs. NP } & \multicolumn{2}{|c|}{ SUS vs. NP } & \multicolumn{2}{|c|}{ BA vs. NP } \\
\hline & $\mathrm{Q}^{+}$ & $\mathrm{p}^{+}$ & $\mathrm{Q}^{+}$ & $\mathrm{p}^{+}$ & $\mathrm{Q}^{+}$ & $\mathrm{p}^{+}$ & $\mathrm{Q}^{+}$ & + \\
\hline \multicolumn{9}{|c|}{ After 36 months since start-up } \\
\hline 1.00 & 4.964 & 0.000 & 7.894 & 0.000 & 6.782 & 0.000 & 10.631 & 0.000 \\
\hline 1.25 & 3.591 & 0.000 & 6.348 & 0.000 & 5.186 & 0.000 & 8.833 & 0.000 \\
\hline 1.50 & 2.490 & 0.006 & 5.119 & 0.000 & 3.904 & 0.000 & 7.400 & 0.000 \\
\hline 1.75 & 1.569 & 0.058 & 4.102 & 0.000 & 2.833 & 0.002 & 6.213 & 0.000 \\
\hline 2.00 & 0.777 & 0.219 & 3.233 & 0.001 & 1.913 & 0.028 & 5.200 & 0.000 \\
\hline \multicolumn{9}{|c|}{ Critical values } \\
\hline $1 \%$ & \multicolumn{2}{|c|}{$1.50-1.55$} & \multicolumn{2}{|c|}{$2.30-2.35$} & \multicolumn{2}{|c|}{$1.85-1.90$} & \multicolumn{2}{|c|}{$2.90-2.95$} \\
\hline $5 \%$ & \multicolumn{2}{|c|}{$1.70-1.75$} & \multicolumn{2}{|c|}{$2.55-2.60$} & \multicolumn{2}{|c|}{$2.05-2.10$} & \multicolumn{2}{|c|}{-} \\
\hline $10 \%$ & \multicolumn{2}{|c|}{$1.80-1.85$} & \multicolumn{2}{|c|}{$2.70-2.75$} & \multicolumn{2}{|c|}{$2.15-2.20$} & \multicolumn{2}{|c|}{-} \\
\hline \multicolumn{9}{|c|}{ After 56 months since start-up } \\
\hline 1.00 & 3.721 & 0.000 & 8.596 & 0.000 & 4.473 & 0.000 & 10.332 & 0.000 \\
\hline 1.25 & 2.355 & 0.009 & 7.163 & 0.000 & 2.862 & 0.002 & 8.616 & 0.000 \\
\hline 1.50 & 1.252 & 0.105 & 6.034 & 0.000 & 1.558 & 0.060 & 7.254 & 0.000 \\
\hline 1.75 & 0.325 & 0.372 & 5.107 & 0.000 & 0.460 & 0.323 & 6.128 & 0.000 \\
\hline 2.00 & 0.307 & 0.379 & 4.321 & 0.000 & 0.346 & 0.364 & 5.169 & 0.000 \\
\hline \multicolumn{9}{|c|}{ Critical values } \\
\hline $1 \%$ & \multicolumn{2}{|c|}{$1.25-1.30$} & \multicolumn{2}{|c|}{$2.80-2.85$} & \multicolumn{2}{|c|}{$1.30-1.35$} & \multicolumn{2}{|c|}{ - } \\
\hline $5 \%$ & \multicolumn{2}{|c|}{$1.40-1.45$} & \multicolumn{2}{|c|}{ - } & \multicolumn{2}{|c|}{$1.45-1.50$} & \multicolumn{2}{|c|}{ - } \\
\hline $10 \%$ & \multicolumn{2}{|c|}{$1.45-1.50$} & \multicolumn{2}{|c|}{ - } & 1.55 & 1.60 & & \\
\hline
\end{tabular}

Note: Reported results are achieved by using mhbounds.ado (see Becker and Caliendo, 2007). Critical values are related to the exact values of $\Gamma$ at which results turn insignificant. BA - Bridging Allowance, SUS - Start-up Subsidy, NP - Non-Participation. 
Figure A.1: Propensity Score Distributions

Start-up Subsidy vs. Non-Participation

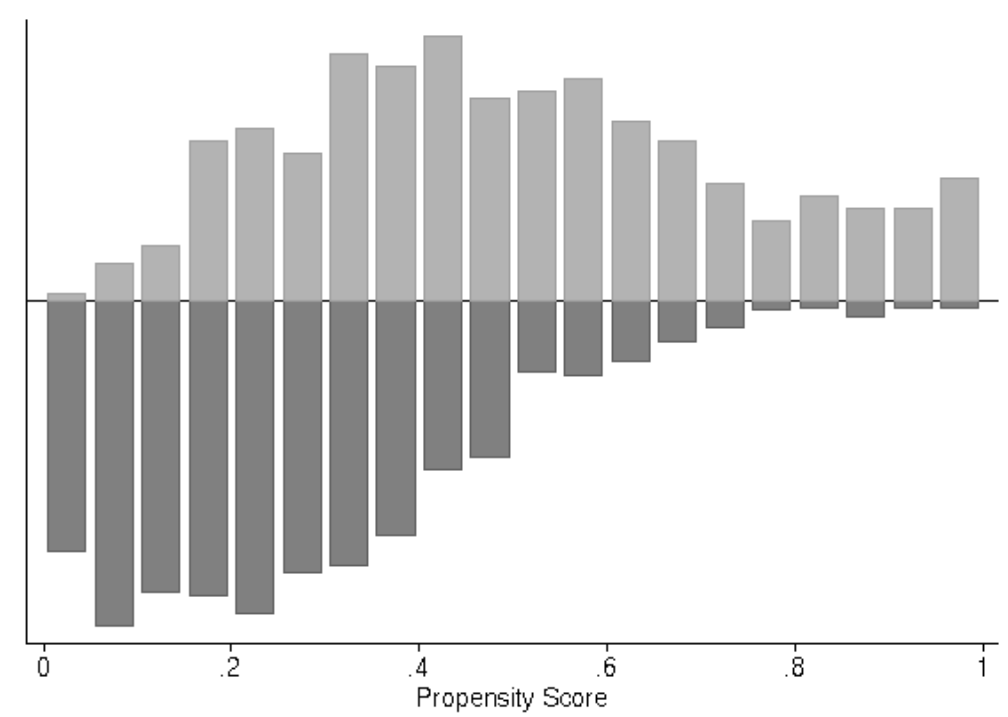

Bridging Allowance vs. Non-Participation

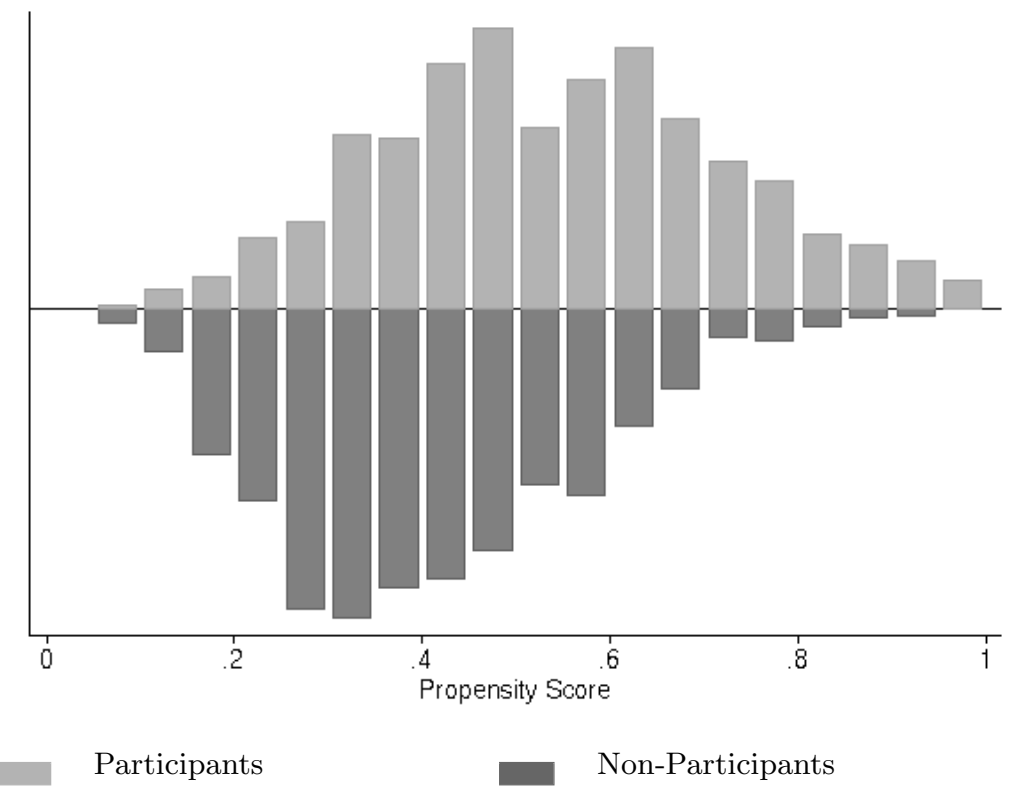

Note: These are propensity score distributions for participants and nonparticipants based on estimations in Table A.2. 
Figure A.2: Effect Heterogeneity: Probability Levels Among Participants and Non-Participants

Start-up Subsidy vs. Non-Participation

Bridging Allowance vs. Non-Participation

Educational level (low-black / high-gray)
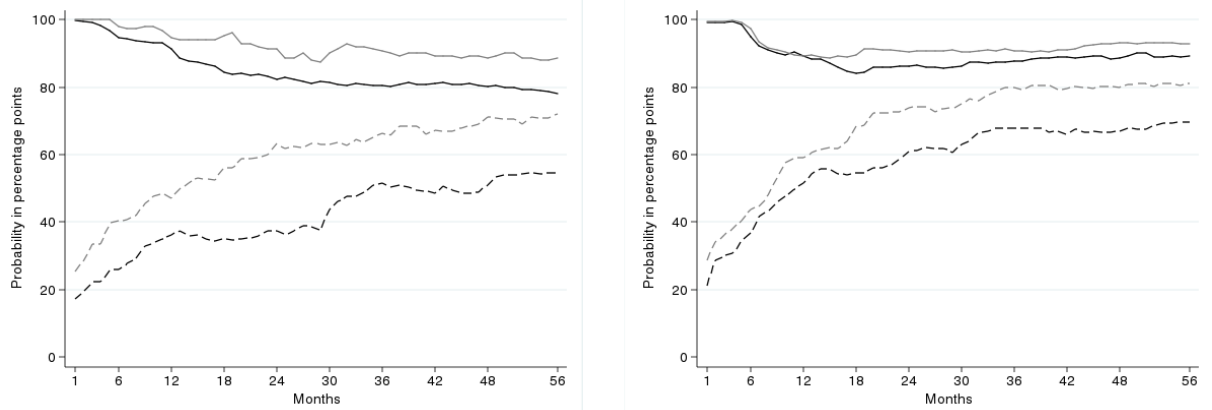

Professional qualification (low-black / high-gray)
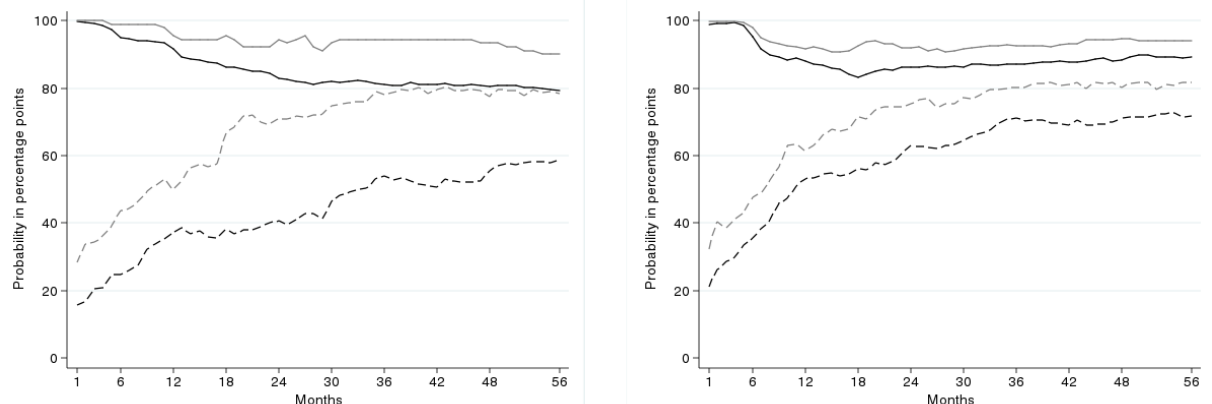

Age $(\leq 30-$ black / >30-gray)
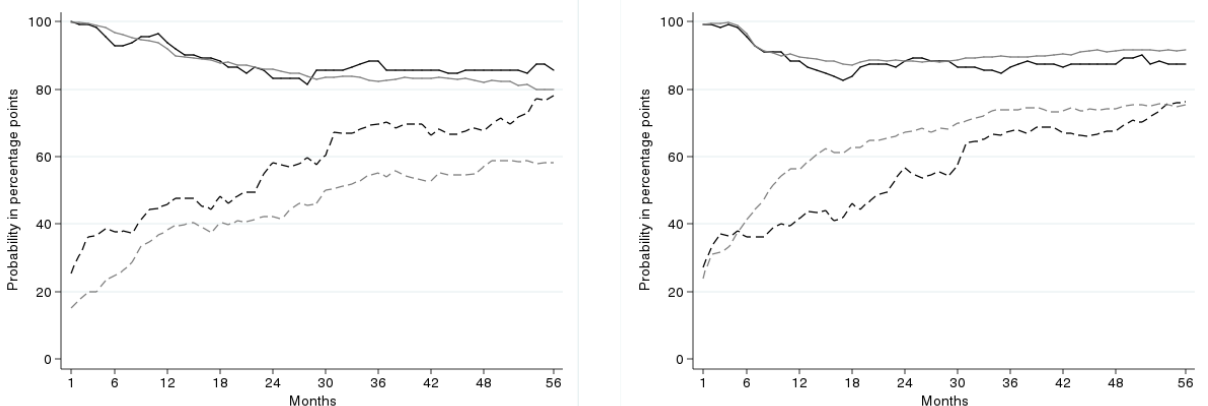

Nationality (German-black / Non-German-gray)
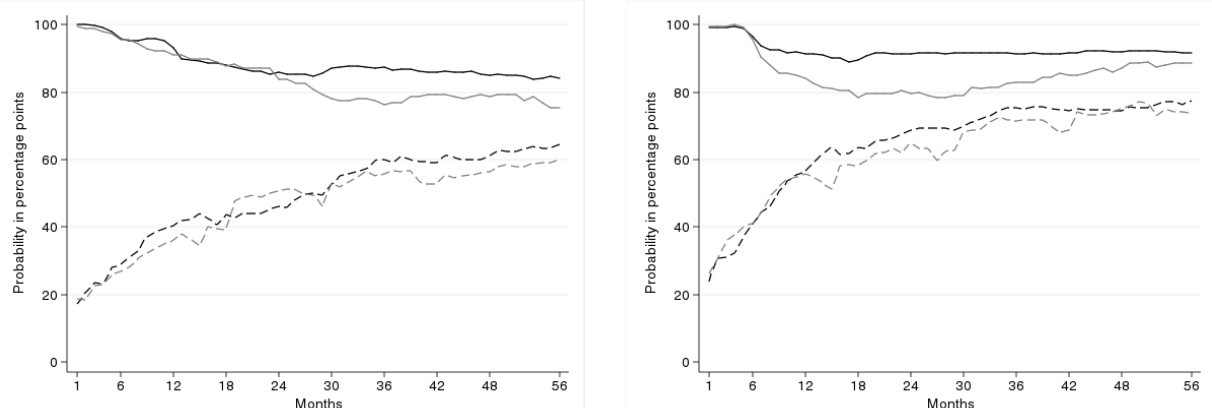

Treated Controls - - -

Note: Depicted are probability levels for the outcome variable "self-employment or regular employment" among participants and non-participants within the matched sample, i.e., the difference between the solid and dashed line is the average treatment effect on the treated. 